\title{
The Role of the Divergent Amino and Carboxyl Domains on the Inactivation Properties of Potassium Channels Derived from the Shaker Gene of Drosophila
}

\author{
Linda E. Iverson ${ }^{1}$ and Bernardo Rudy ${ }^{2}$ \\ 1Division of Neurosciences, Beckman Research Institute of the City of Hope, Duarte, California 91010, and ${ }^{2}$ Departments \\ of Physiology and Biophysics and of Biochemistry, New York University Medical Center, New York, New York 10016
}

\begin{abstract}
Several products generated from the Drosophila Shaker gene by alternative splicing predict a group of similar proteins with an identical central and variable amino and carboxyl domains. We have constructed 9 Sh cDNAs combining 3 different $5^{\prime}$ domains with 3 different $3^{\prime}$ domains. RNA transcribed from 6 of these cDNAs induce $\mathrm{K}^{+}$currents in Xenopus oocytes. All currents share similar properties of voltage dependence, potassium selectivity, and block by 4-AP, TEA, and charybdotoxin. These properties presumably result from a channel core formed by the identical central region of the proteins. The currents differ in macroscopic inactivation kinetics. Five RNAs induced $K^{+}$currents which inactivate, each at distinct rates, during short depolarizations. The sixth RNA induces a current that essentially does not inactivate unless depolarized for many seconds. This raises the possibility that $S h$ may encode nontransient as well as transient $K^{+}$ currents. Analysis of currents produced by the various combinations suggests that the divergent amino domains influence the stability of a first, nonabsorbing, inactivated state. This results in striking differences in the probability of channel reopening, as observed in single-channel recordings, of those channels with identical carboxyl but different amino domains. Furthermore, based on macroscopic analysis of the currents, we suggest that the primary role of the carboxyl domains is to influence the relative stability between the first and a second inactivated state. The second inactivated state is essentially absorbing, and recovery from this state is very slow. The observed differences in the rates of recovery from inactivation of channels containing different carboxyl domains reflect differences in the rates at which they enter this second inactivated state.
\end{abstract}

\footnotetext{
Received Nov. 16, 1989; revised Apr. 20, 1990; accepted Apr. 25, 1990.

We thank Kenneth J. McCormack, Mani Ramaswami, Erwin Neher, and Henry Lester for helpful discussions and comments on the manuscript; Jen Wei Lin for his collaboration on the experiments shown in Figure 8; Eleazar Vega for his help in writing the simulation programs; and Elizabeth Sable for technical assistance. We also thank Bill Zagotta and Rick Aldrich for communicating their results prior to publication. Construction of chimeric $S h$ cDNAs and initial characterization of some of the currents were carried out while L.I. was a postdoctoral fellow in Mark Tanouye's laboratory at Caltech and B.R. was a visiting professor in Henry Lester's and Norman Davidson's laboratories at Caltech. We therefore wish to acknowledge their support and encouragement. This research was supported by U.S. Public Service grants GM26976 to B.R., NS21327 to Mark Tanouye, NS1 1756 to Henry Lester, and funds provided by the Beckman Research Institute of the City of Hope to L.I.

Correspondence should be addressed to Dr. B. Rudy, Department of Physiology, NYU Medical Center, 550 First Avenue, New York, NY 10016.

Copyright $(1990$ Society for Neuroscience $0270-6474 / 90 / 092903-14 \$ 03.00 / 0$
}

Potassium $\left(\mathrm{K}^{+}\right)$channels comprise an exceptionally diverse family of ion channels (Hille, 1984; Adams and Galvan, 1986; Rudy, 1988). Among the class of $\mathrm{K}^{+}$channels activated by membrane depolarization (voltage-dependent $\mathrm{K}^{+}$channels), a number of different subtypes have been identified. The different $\mathrm{K}^{+}$channel subtypes show variability in their kinetics of activation and inactivation, the membrane potential at which the channels open and close, and their responses to various drugs, toxins, hormones, and second messengers. Because of their prevalence and diversity in the nervous system, $\mathrm{K}^{+}$channels play a leading role in controlling neuronal activity. Indeed, different classes of $\mathrm{K}^{+}$channels have been shown to underlie the generation of diverse neuronal firing patterns, to influence the shape of action potential waveforms, and to modify synaptic efficacy (Adams and Galvan, 1986; Klein et al., 1982; Llinás, 1984). An understanding of the structural elements involved in determining functional propertics of $\mathrm{K}^{+}$channels is cssential for detcrmining the molecular basis of $\mathrm{K}^{+}$channel diversity and, in turn, may provide important details as to how these channels participate in regulating various aspects of neuronal function.

Understanding the molecular basis of $\mathrm{K}^{+}$channel diversity requires systematic structure-function studies of a number of different $\mathrm{K}^{+}$channels in isolation. This is most easily accomplished using a combination of molecular analysis of $\mathrm{K}^{\prime}$ channel genes and electrophysiological analysis of the encoded channels. These studies have been hindered in the recent past by the lack of any $\mathrm{K}^{+}$channel cDNAs. However, recent experiments have shown that RNAs transcribed in vitro from cDNAs of the Shaker $(S h)$ locus of Drosophila melanogaster induce functional $\mathrm{K}^{+}$ channels when injected into Xenopus oocytes (Iverson et al., 1988; Timpe et al,, 1988a). Based on homology to ShakercDNA sequences a number of other $\mathrm{K}^{+}$channel cDNAs have been isolated from mouse (Tempel et al., 1988), rat (Baumann ct al., 1988), Drosophila (Butler et al., 1989), and human (Mathew et al., 1989).

Molecular analysis of $S h$ indicates that the gene encodes a family of related transcripts that arise by an alternative splicing mechanism in which variable $5^{\prime}$ and $3^{\prime}$ domains are joined to a conserved central region (Kamb et al., 1988; Pongs et al., 1988; Schwarz et al., 1988). Several functionally distinct $\mathrm{K}^{+}$ currents have been expressed in Xenopus oocytes injected with Sh RNAs (Iverson et al., 1988; Timpe et al., 1988a,b; Zagotta et al., 1989b). All $S h$ encoded $\mathrm{K}^{+}$currents show similar properties of $\mathrm{K}^{+}$selectivity, voltage dependence, and sensitivity to 4-aminopyridine (4-AP), but are markedly different in their kinetics of inactivation and recovery from inactivation. We sug- 
gested previously that the variable amino-terminal domains influence primarily the rate of onset of inactivation, while the divergent carboxyl-terminal domains influence primarily the rate of recovery from inactivation (Iverson et al., 1988). This conclusion was based mainly on the kinetic properties of currents induced by one Sh RNA, H37, which inactivates extremely slowly. Based on sequence analyses, the H37 RNA encodes a protein with the same carboxyl domain as the ShA RNA, previously expressed by Timpe et al. (1988a). Because currents induced by ShA RNA appear to inactivate relatively fast, we therefore concluded that the slow rate of inactivation of currents induced by H37 RNA was due to the fact that these RNAs encode proteins with different amino termini. However, at that time we did not have a cDNA equivalent to ShA, nor did there exist a cDNA encoding the same amino terminus of $\mathrm{H} 37$ in combination with a different carboxyl terminus that could be expressed in oocytes. Because $S h$ cDNAs containing all amino domains in combination with all possible carboxyl domains did not exist at that time, it was not possible to ascertain the role the various domains play in determining inactivation properties of the channels.

By making use of unique restriction enzyme cleavage sites we have constructed 9 chimeric $S h$ cDNAs containing 3 of the 5 identified 5 ' domains in all possible combinations with 3 of the 4 identified 3' domains. RNA synthesized in vitro from 6 of the cDNA templates express $\mathrm{K}^{\prime}$ currents in Xenopus oocyles. Five of the chimeras express transient $\mathrm{K}^{+}$currents, albeit with different kinetic properties, that are similar to all previously reported A-type $\mathrm{K}^{+}$currents encoded at the $S h$ locus. However, one cDNA induces an essentially noninactivating $\mathrm{K}^{+}$current that is unlike any previously reported $S h \mathrm{~K}^{+}$current. This nontransient current exhibits properties of voltage dependence, $\mathrm{K}^{+}$ selectivity, and pharmacology that are similar to all Sh encoded transient $\mathrm{K}^{+}$currents. It is expressed from a Sh RNA that encodes the same amino domain as $\mathrm{H} 37$, which exhibits the slowest onset of inactivation, in combination with the carboxyl domain of $\mathrm{H} 4$, which exhibits the fastest inactivation recovery. Our results show that by generating particular combinations of amino and carboxyl domains, both transient and nontransient currents can be expressed from $S h$ RNAs. The availability of the different chimeric cDNAs has allowed us to distinguish the roles of the amino and carboxyl domains in inactivation kinetics and to generate one possible kinetic model for $S h \mathrm{~K}^{+}$channel inactivation that accounts for both the transient and nontransient $\mathrm{K}^{+}$currents.

\section{Materials and Methods}

Construction of $5^{\prime}-3^{\prime} C D N A$ chimeras and in vitro synthesis of RNA. Chimeric cDNAs were generated by restriction enzyme digestion and religation of BlueScript (Stratagene, La Jolla) plasmids containing 3 different $S h$ cDNA inserts. The parental cDNAs were $\mathrm{H} 4, \mathrm{H} 29$, and $\mathrm{H} 37$ (Kamb et al., 1988). The H37 cDNA in BlueScript was originally isolated with the $5^{\prime}$ end of the sense strand adjacent to the T3 promoter of the vector (Iverson et al., 1988). The orientation of the $\mathrm{H} 37$ insert was switched to match that of $\mathrm{H} 4$ and $\mathrm{H} 29$ cDNAs (with the $5^{\prime}$ end of the sense strand adjacent to the T7 promoter), by digestion with EcoR1 followed by ligation and restriction enzyme mapping of the reisolated plasmids. The original $\mathrm{H} 4 \mathrm{cDNA}$ was modified to increase the level of expression of H4 RNA in Xenopus oocytes. This was accomplished by removal of most of the $5^{\prime}$ untranslated sequences by digestion with restriction enzymes PflmI (which cleaves the plasmid once at a site located 5 nucleotides to the $5^{\prime}$ side of the $\mathrm{H} 4$ start codon) and SmaI (which cleaves the plasmid once at a site within the BlueScript polylinker, adjacent to the 5' end of the cDNA), removal of the PflmI 3' overhang by treatment with T4 DNA polymerase, followed by joining of the 2 blunt ends by overnight incubation with T4 DNA ligase (Boehringer). RNA prepared from the modified $\mathrm{H} 4$ cDNA (H4[U5']) and injected into Xenopus oocytes generally gives rise to currents about 2to 3-fold greater in amplitude than that observed in oocytes injected with equivalent amounts of the original H4 RNA (unpublished observations). The $\mathrm{H} 4\left[\mathrm{U} 5^{\prime}\right] \mathrm{cDNA}$ was a generous gift from Dr. Reid Leonard and was used to construct 4-29, 4-37, 29-4, and 37-4 chimeras.

RNA was prepared from cDNA templates that had been digested with HindIII, incubated for $15 \mathrm{~min}$ at $37^{\circ} \mathrm{C}$ with proteinase $\mathrm{K}(50 \mu \mathrm{g} /$ $\mathrm{ml}$ ) and SDS (0.4\%), extracted twice with an equal volume of a $1: 1$ mixture of phenol : chloroform, extracted once with ether, made $0.3 \mathrm{M}$ with sodium acetate, $\mathrm{pH} 5.2$, and precipitated with 2.5 volumes of EtOH. Transcription reactions were carried out at $37^{\circ} \mathrm{C}$, for $2-4 \mathrm{hr}$, in $150 \mu \mathrm{l}$ reactions containing $40 \mathrm{~mm}$ Tris $-\mathrm{Cl}(\mathrm{pH} 7.5), 6 \mathrm{~mm} \mathrm{MgCl}, 2$ $\mathrm{mm}$ spermidine (Sigma), $10 \mathrm{~mm} \mathrm{NaCl}, 10 \mathrm{~mm}$ dithiothreitol (Sigma, prepared fresh), 140 units Human Placental RNase inhibitor (RNAsin, Promega), $0.5 \mathrm{~mm}$ diguanosine $5^{\prime}-5^{\prime}$ triphosphate ( $\mathrm{pH} 7.5$, Pharmacia), $0.5 \mathrm{mM}$ ATP, $0.5 \mathrm{~mm}$ CTP, $0.5 \mathrm{~mm}$ UTP, $0.1 \mathrm{~mm}$ GTP (all ribonucleoside triphosphates were obtained as $100 \mathrm{~mm}$, RNase-free, buffered aqueous solutions from Pharmacia), 1-3 $\mu \mathrm{g}$ of template cDNA, and 2060 units of T7 RNA polymerase (Promega). Following in vitro synthesis of RNA, cDNA templates were destroyed by $15 \mathrm{~min}$ incubation at $37^{\circ} \mathrm{C}$ with 5 units DNasel (RQ1, RNase free, Promega). Unincorporated ribonucleoside triphosphates were removed by passing the reaction mixture through G 50-80 Sephadex (Pharmacia) spun columns. RNA was extracted twice with a $1: 1$ mixture of phenol : chloroform, made $0.3 \mathrm{M}$ with sodium acetate ( $\mathrm{pH} 5.2$ ), and precipitated with 2.5 volumes of absolute ethanol. Following centrifugation, RNA pellets were washed twice with $70 \%$ ethanol and resuspended in distilled $\mathrm{H}_{2} \mathrm{O}$ to give a final concentration of approximately $10 \mathrm{ng} / 50 \mathrm{nl}$. RNA yields were determined from the amount of $\alpha-{ }^{32} \mathrm{P}$-UTP (Amersham) incorporated into RNA in $10 \mu \mathrm{l}$ aliquots of the transcription reactions. Following denaturation, by $15 \mathrm{~min}$ incubation at $55^{\circ} \mathrm{C}$ in $50 \%$ formamide, ${ }^{32} \mathrm{P}$-labeled RNA samples were electrophoresed on $1 \%$ agarose, $6.6 \%$ formaldehyde gels. In every case, single bands of the expected size for full-length transcripts were observed on autoradiograms of the gel.

$R N A$ injection and electrophysiological recording. Adult female Xenopus laevis were anesthetized in $0.17 \%$ MS-222 (tricaine methanesulfonate, Sigma) and a section of the ovary surgically removed. Oocytes were dissociated by $2-3 \mathrm{hr}$ treatment with $2 \mathrm{mg} / \mathrm{ml}$ collagenase (type lA, Sigma) in a solution containing $82.5 \mathrm{~mm} \mathrm{NaCl}, 2.0 \mathrm{mM} \mathrm{KCl}, 1.0$ $\mathrm{mM} \mathrm{MgCl}_{2}$, and $5.0 \mathrm{mM}$ HEPES (pH 7.5). The collagenase treatment also results in removal of the overlying follicle layer in $50-70 \%$ of the oocytes. Defolliculated stage V and VI oocytes (Dumont, 1972) were selected and placed in ND96 $(96.0 \mathrm{~mm} \mathrm{NaCl}, 2.0 \mathrm{~mm} \mathrm{KCl}, 1.8 \mathrm{~mm}$ $\mathrm{CaCl}_{2}, 1.0 \mathrm{~mm} \mathrm{MgCl}_{2}, 5.0 \mathrm{~mm}$ HEPES, pH 7.5) supplemented with penicillin ( $100 \mathrm{units} / \mathrm{ml})$, streptomycin $(100 \mu \mathrm{g} / \mathrm{ml})$, and $2.5 \mathrm{~mm}$ sodium pyruvate. The oocytes were injected $5-24 \mathrm{hr}$ following selection with $50 \mathrm{nl}$ RNA (approximate concentration $200 \mathrm{ng} / \mathrm{ml}$ in distilled $\mathrm{H}_{2} \mathrm{O}$ ) using a micropipettor (Drummond) and incubated in the above solution for $2-3 \mathrm{~d}$ at $18-20^{\circ} \mathrm{C}$ prior to recording.

Macroscopic currents were recorded using a standard 2-microelectrode voltage clamp. Voltage and current electrodes were filled with 3 $\mathrm{M} \mathrm{KCl}$ and had resistances of less than $1 \mathrm{M} \Omega$. The electrode potential was nulled in the bath prior to penetration. A ground shield, placed between the current and voltage electrodes, was used to decrease electrode coupling. The recording chamber was continually perfused with ND96, with or without the addition of 4-AP (Sigma), tetraethylammonium (TEA; Sigma, recrystallized), or charybdotoxin (CTX; a generous gift from Dr. C. Miller). All experiments were carried out at room temperature, $20-22^{\circ} \mathrm{C}$. Current signals were low-pass-filtered at $3 \mathrm{kHz}$ using an 8-pole Bessel filter. The leakage current was estimated from the average current response to $10 \mathrm{mV}$ voltage steps between -100 and $-80 \mathrm{mV}$. No time-dependent currents were activated in this voltage range. Single-channel records were obtained using the cell-attached configuration of the patch-clamp technique (Hamill et al., 1981) using an Axopatch amplifier (Axon Instruments, Foster City, CA). Patch pipettes, with input resistances of 5-15 M $\Omega$, were made of borosilicate glass and filled with ND96. The pipette potential was zeroed just prior to seal formation. A single microelectrode was placed in the oocyte to monitor the resting potential throughout the experiment. The pCLAMP system (Axon Instruments) was used to run voltage-clamp protocols and to digitize and analyze current records. Simulations were obtained from numerical solutions of the differential equations for the model utilizing 


\begin{tabular}{|c|c|c|c|c|c|}
\hline 3 & 4 & 29 & 37 & $\boldsymbol{C}$ & $\delta$ \\
\hline 4 & $\begin{array}{c}-4^{\mathrm{a}} \\
\mathrm{H} 4^{\mathrm{bc}} \\
\text { Sh B } \\
-{ }_{-}^{\mathrm{d}}\end{array}$ & $\begin{array}{l}29-4^{\mathrm{a}} \\
\mathrm{Sh} \mathrm{D}^{\mathrm{c}} \\
\mathrm{S} \beta^{\mathrm{C}}\end{array}$ & $37-4^{a}$ & 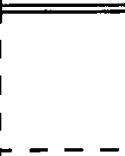 & i \\
\hline 37 & $\begin{array}{l}4-37^{\mathrm{a}} \\
\operatorname{Sh~} A^{\mathrm{d}} \\
\operatorname{Sh} \alpha^{\mathrm{e}}\end{array}$ & $29-37$ & $\begin{array}{l}\mathrm{a}_{1} 37-37^{\mathrm{a}} \\
\mathrm{H} 37^{\mathrm{bc}} \\
1\end{array}$ & $\mathrm{ShC}^{\mathrm{d}}$ & \\
\hline 29 & $4-29^{a}$ & $\begin{array}{l}29-29^{a} \\
H 29^{c}\end{array}$ & $\begin{array}{l}137-29^{2} \\
1\end{array}$ & & \\
\hline 2 & $\operatorname{Sh} \varepsilon^{e}$ & E1 ${ }^{b c}$ & $\mathrm{H} 2^{b c}$ & & $\operatorname{Sh} \delta^{\mathrm{e}}$ \\
\hline
\end{tabular}

Figure 1. Nomenclature of Sh cDNAs. 5' domains are listed in the top row, $3^{\prime}$ domains in the left-hand column. RNA transcribed from the 7 cDNAs in the boxed region have been shown to induce potassium currents in Xenopus oocytes. References describing sequences of the various proteins and properties of the expressed currents are as follows: (a) this paper, (b) Iverson et al. (1988), (c) Kamb et al. (1988), (d) Timpe et al (1988a, h) and Schwarz et al. (1988), and (e) Pongs et al. (1988).

a program written in TURBO BASIC. Time constants of inactivation of the simulatef currents were obtained from exponential fits using ASYSTANT (McMillan).

\section{Results}

\section{Diversity of Shaker gene products}

All $S h$ cDNAs contain a conserved central region flanked by variable 5' and 3' domains (Kamb et al., 1988; Pongs et al., 1988; Schwarz et al., 1988). At least 5 distinct $5^{\prime}$ domains and 4 distinct $3^{\prime}$ domains have been described. If the variable $5^{\prime}$ and $3^{\prime}$ domains assort independently, this would predict a minimum of 20 different $S h$ transcripts. Different laboratories have used various nomenclature systems to identify the different $S h$ cDNAs. In this report we will use a nomenclature system that will identify, for each cDNA, the type of $5^{\prime}$ and $3^{\prime}$ domain present. The $S h$ cDNAs described here and their equivalence to $S h$ cDNAs isolated and characterized by other laboratories are shown in Figure 1.

Protein coding regions of all $S h$ transcripts initiate in the variable $5^{\prime}$ domains, extend through the constant region, and terminate in the variable $3^{\prime}$ domains, yielding a group of similar proteins with distinct amino and carboxyl termini. Two basic types of $S h$ proteins have been described (Kamb et al., 1988; Pongs et al., 1988). The predicted proteins encoded by long $S h$ transcripts (types 4,29 , or $373^{\prime}$ domains) contain five potential membrane-spanning hydrophobic regions. In addition, these proteins contain a sequence similar to the $\mathrm{S} 4$ sequence, present in both sodium and calcium channels, that is believed to form a membrane-spanning amphipathic helix involved in voltage sensing (Noda et al., 1984, 1986; Guy and Seetharamulu, 1986; Catterall, 1986). RNA transcribed from several of the long cDNAs has been shown to express functional $\mathrm{K}^{+}$channels in Xenopus oocytes (Iverson et al., 1988; Timpe et al., 1988a, b). The predicted proteins encoded by short $S h$ cDNAs (those with a type $23^{\prime}$ domain) terminate in the constant region after the third hydrophobic domain and contain no S4-like sequence (Kamb et al., 1988; Pongs et al., 1988). $\mathrm{K}^{+}$currents have not been observed in oocytes injected with $S h$ RNAs containing short $3^{\prime}$ domains (Iverson et al., 1988), so the functional role, if any, of these short gene products is not known.

\section{Shaker $K^{+}$channel diversity}

Using $S h$ cDNAs containing the three $5^{\prime}$ domains available to us (types 4, 29, and 37) and all three of the long $3^{\prime}$ domains (types 4,29 , and 37), we have constructed 9 possible combinations of divergent $5^{\prime}$ and $3^{\prime}$ domains by the strategy outlined in Figure 2. Four of the chimeras represent new $5^{\prime}-3^{\prime}$ combinations that have not been isolated from Drosophila cDNA libraries (4-29, 29-37, 37-4, and 37-29). RNA transcripts of the 9 cDNAs were synthesized in vitro and injected into Xenopus oocytes. Six of the 9 transcripts induce functional $\mathrm{K}^{+}$channels. Transcripts containing a type $29 \mathbf{3}^{\prime}$ domain consistently fail to induce $\mathrm{K}^{+}$currents in Xenopus oocytes, and this failure to express is independent of the $5^{\prime}$ domain.

Examples of currents expressed in Xenopus oocytes injected with the 6 RNAs are shown in Figure 3. All 6 RNAs induce outward currents that activate relatively quickly. Although the rate of current rise is somewhat variable, the 6 currents differ markedly in the rate at which they inactivate. Differences in inactivation kinetics are particularly striking if one compares currents in the same row (identical carboxyl domain, different amino domains). However, differences are also apparent if one compares currents in the same column (identical amino domain, different carboxyl domains). These results indicate that although both domains influence the kinetics of macroscopic inactivation, the amino domain appears to dictate a general range of inactivation properties: channels containing type 4 amino domains inactivate fast, type 29 is intermediate, and those containing type 37 amino domains appear to inactivate slowly, or not at all.

The 4-4 current inactivates the fastest. Three of the $S h$ RNAs (4-37, 29-4, and 29-37) induce currents that are similar, although not identical, to the 4-4 current in the rate at which they inactivate. In contrast, the 37-37 current does not fully inactivate during the $50 \mathrm{msec}$ pulse shown here. However, this current will inactivate completely during test depolarizations of 500 msec (figure 1, Iverson et al., 1988; see also Fig. 5). The sixth RNA, 37-4, induces an essentially noninactivating current. Currents induced by 37-4 RNA show a small, transient component only at the beginning of the pulse and only at large membrane depolarizations. The majority of the 37-4 current remains at a steady-state level even though the pulse duration is twice that shown for the other currents $(100 \mathrm{msec})$. The $37-4$ current will inactivate further during test depolarizations that last several seconds (data not shown). We believe this slow inactivation is real because it is identical in oocytes expressing very different amounts of current (at test potentials of $0 \mathrm{mV}$ or below). The unusually large steady-state current observed during short depolarizations in oocytes injected with 37-4 RNA is an extreme example of a phenomenon of incomplete inactivation that has been seen for all $S h$ currents expressed from RNAs containing a type $43^{\prime}$ domain, and is discussed in more detail below.

Because of the large capacitance of the oocyte membrane, space-clamp artifacts may alter current kinetics and lead to false differences among currents expressed from different RNAs. However, kinetic properties of currents expressed from a par- 


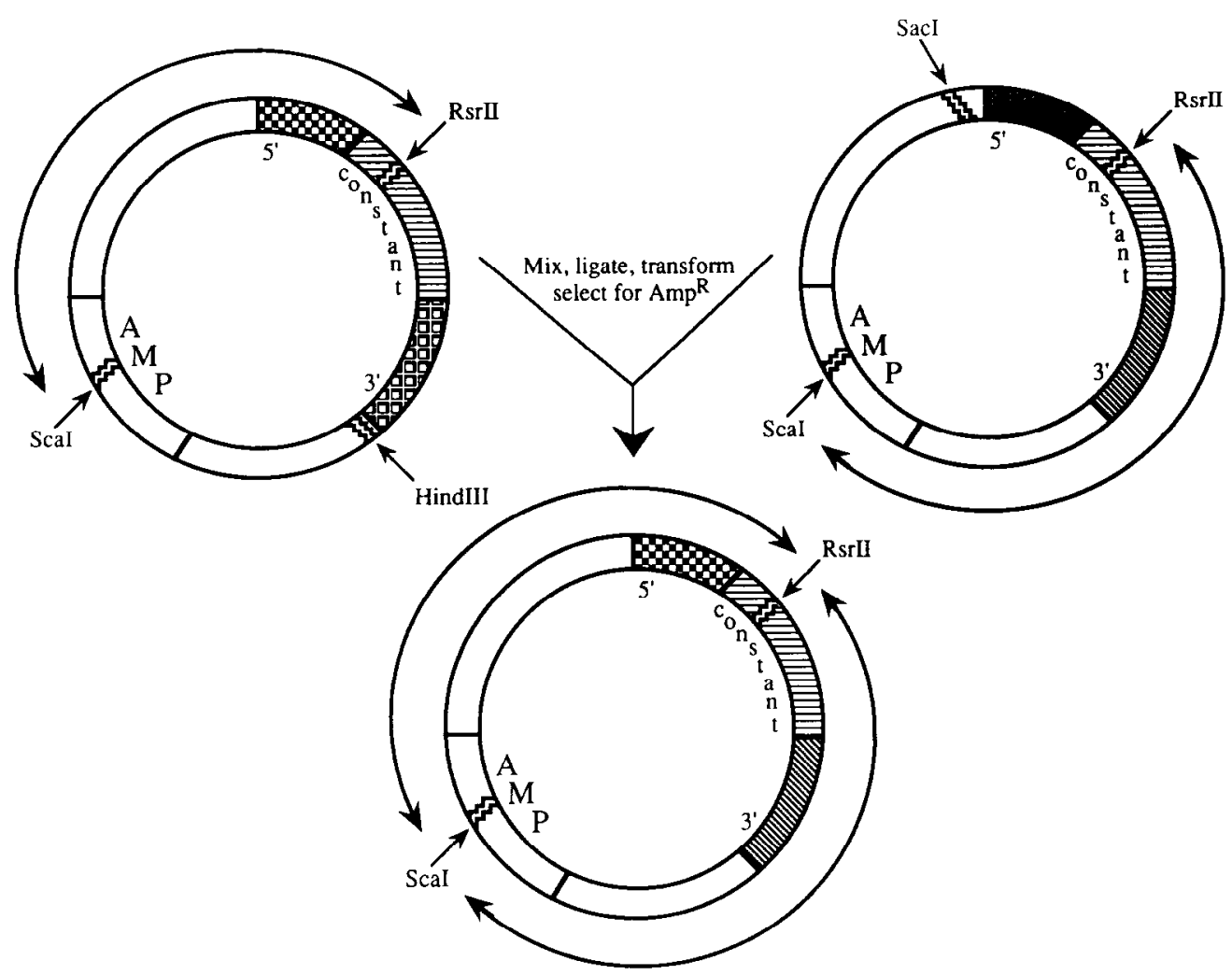

Figure 2. Construction of chimeric cDNAs. Chimeric cDNAs were constructed using the following strategy: (1) Plasmid DNAs containing the 5 ' domain of interest were digested with the restriction enzymes RsrII (which cleaves once in the constant region of all $S h$ cDNAs), HindIII (which cleaves once in the polylinker of the BlueScript, adjacent to the $3^{\prime}$ end of the cDNAs), and Scal (which cleaves once in the ampicillin gene (AMP) within the BlueScript vector); (2) plasmid DNAs containing the $3^{\prime}$ domain of interset were digested with restriction enzymes RsrII, ScaI, and SacI (which cleaves once in the polylinker of the vector adjacent to the $5^{\prime}$ end of the cDNA); (3) approximately $0.5 \mu \mathrm{g}$ DNA obtained from steps 1 and 2 above were mixed, incubated at $14^{\circ} \mathrm{C}$ overnight with T4 DNA ligase (Boehringer), and used to transform $E$. coli DH5 $\alpha$ cells to ampicillin resistance. Although the chimeric cDNAs were not sequenced, extensive restriction enzyme mapping indicated that they had the expected 5 and $3^{\prime}$ domains. In addition, 29-4 and 37-4 chimeras were also constructed using a strategy identical to that described above, except the restriction enzyme BsmI (which cleaves once in the constant region of all long Sh cDNAs) was used in both steps 1 and 2 instead of RsrII. Currents expressed in oocytes injected with RNA prepared from these cDNA chimeras exhibited kinetic properties of inactivation that were identical to those expressed from RNA derived from the original 29-4 and 37-4 cDNAs. The inclusion of restriction enzymes HindIII (in step 1) and SacI (in step 2) reduces the probability of reisolating the original cDNAs since this will require correct ligation of 3 , as opposed to just 2, DNA fragments. Nevertheless, occasionally the original cDNA was reisolated. In those cases, currents expressed from the original $\mathrm{H} 4$ and $\mathrm{H} 37 \mathrm{cDNAs}$ had the same kinetic properties as the reisolated chimeric cDNAs 4-4 and 37-37.

ticular RNA are qualitatively and quantitatively similar among oocytes expressing currents that differ in amplitude by an order of magnitude ( $500 \mathrm{nA}$ to $5 \mu \mathrm{A}$ ), and in oocytes injected with different amounts of RNA.

\section{Constant properties of Shaker $K^{+}$currents}

Previous results suggested that all $S h$ RNAs express $\mathrm{K}^{+}$currents that are similar in their selectivity for $\mathrm{K}^{+}$ions, their sensitivity to the $\mathrm{K}^{+}$channel blocker 4-aminopyridine, and their voltagedependent propertics that result in similar conductance-voltage relations and steady-state inactivation curves (Iverson et al., 1988; Timpe et al., 1988b). This is also true for the 6 currents described here. The similarity in voltage-dependent properties of the 6 currents is best illustrated by the conductance-voltage relations shown in Figure 4 . In all cases, the conductance starts to rise at membrane potentials between -40 and $-30 \mathrm{mV}$ (Fig. $4 A$ ). The limiting slope of the conductance-voltage curve (Fig. $4 B$ ) predicts a maximum $e$-fold increase in conductance for every $6 \mathrm{mV}$ increase in membrane potential. This value is similar to previously reported values for $S h \mathrm{~K}^{+}$currents expressed in Xenopus oocytes $(5.5-6.5 \mathrm{mV} / e$-fold change in conductance:
Iverson et al., 1988; $6.1 \mathrm{mV} / e$-fold: Timpe et al., 1988b) and $S h$-encoded A currents in Drosophila muscle $(6 \mathrm{mV} / e$-fold: $\mathrm{Wu}$ and Haugland, 1985). However, the method used to determine the limiting slope apparently leads to a 2-fold underestimation of the total gating charge of Shaker channels (Zagotta and Aldrich, 1990). In addition, single-channel records (see Fig. 6, below) indicate that all 3 of the $S h$ channels containing a type 4 carboxyl domain show a similar single-channel conductance. This suggests that single-channel conductance is also a constant property of all $S h$ channels. The 5 inactivating currents described here also exhibit similar steady-state inactivation curves with midpoints of inactivation of about $-35 \mathrm{mV}$ and slopes of approximately $4.5 \mathrm{mV}$ shifts for every $e$-fold change in relative current. All 6 currents display similar properties of $\mathrm{K}^{+}$selectivity, all are completely blocked by $5 \mathrm{~mm}$ 4-aminopyridine, and all are partially blocked by $20 \mathrm{~mm}$ tetraethylammonium ion (data not shown).

A recent report (MacKinnon et al., 1988) demonstrates that perfusion of oocytes injected with 4-4 RNA with 8 nм charybdotoxin (CTX) reduces the amplitude of the $A$ current to about $30 \%$ of the control level. This result is in apparent conflict with 

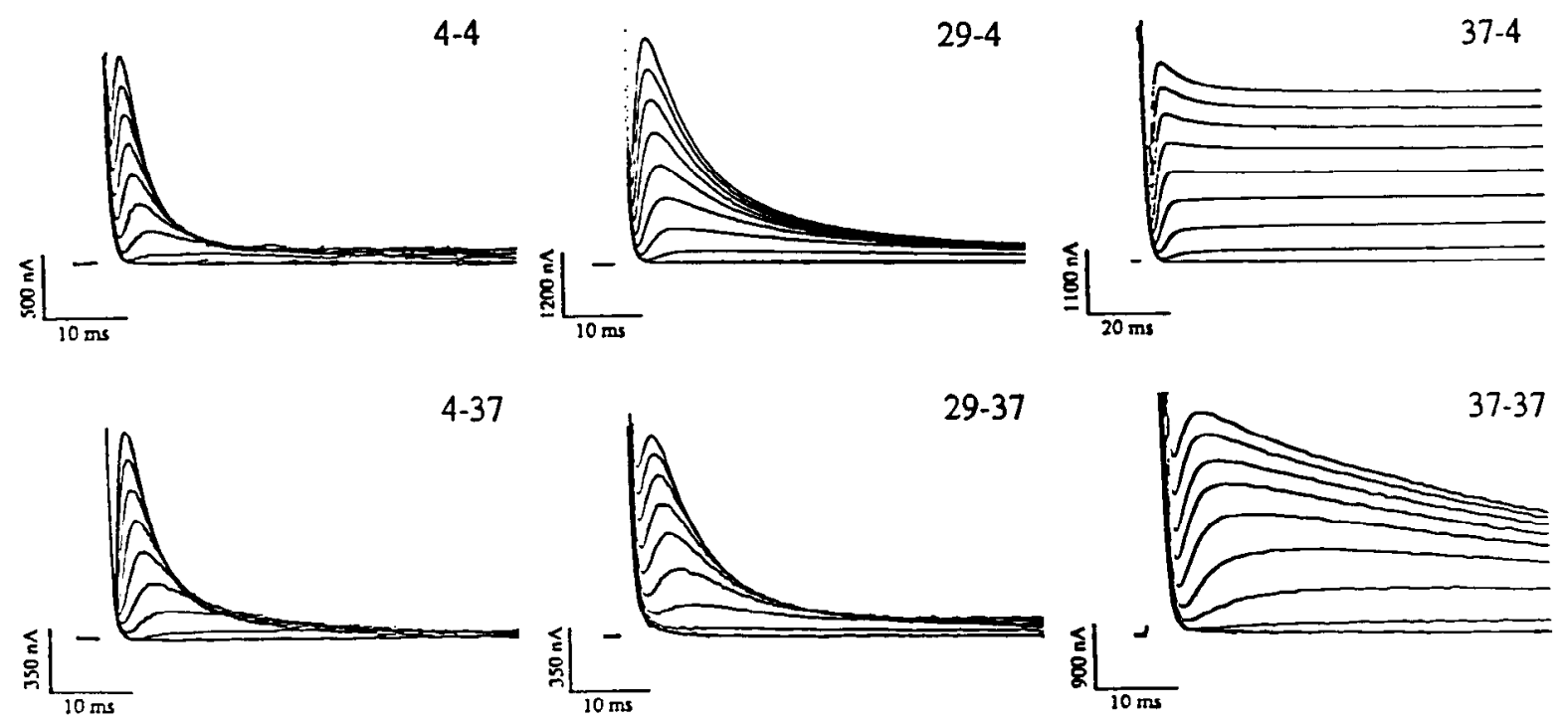

Figure 3 Expression of $\mathrm{K}^{+}$currents in Xenopus oncytes injected with 6 different $S h$ RNAs. The type of $S h$ RNA injected is indicated in the top right corner of each panel. Ion currents were recorded using a 2 -microelectrode voltage clamp. The membrane potential was held at $-90 \mathrm{mV}$, followed by a $1 \mathrm{sec}$ hyperpolarizing pulse to $-120 \mathrm{mV}$, then stepped to test potentials, of the indicated duration, ranging from -60 to $+40 \mathrm{mV}$ in $10 \mathrm{mV}$ increments. Pulses were applied once every $5 \mathrm{sec}$ to oocytes injected with RNAs containing type $43^{\prime}$ ends (4-4, 29-4, and 37-4) and once every $30 \mathrm{sec}$ to oocytes injected with RNAs containing type $373^{\prime}$ ends $(4-37,29-37$, and $37-37)$. Only the currents observed during the test depolarizations are shown here. Identical currents are observed if the oocytes are depolarized directly from $-90 \mathrm{mV}$; however, the 1 sec hyperpolarization to $-120 \mathrm{mV}$ speeds up the recovery from inactivation of currents expressed from RNAs containing type $373^{\prime}$ ends. The records are shown after leak subtraction.

earlier results indicating that $S h$ encoded A currents in Drosophila muscle are insensitive to blockage by CTX, even at concentrations as high as $200 \mathrm{~nm}$ and after allowing $30 \mathrm{~min}$ for diffusion of the drug through the muscle stack (Elkins et al., 1986). One possible reason for this discrepancy is that only one of the Sh RNAs encodes the Drosophila muscle-specific channel. Because we were interested in identifying which, if any, of the channels is muscle specific, we examined the CTX sensitivity of the 6 channels expressed in oocytes. Our results indicate that all 6 currents are similarly blocked by CTX with a $K_{d} \sim 6 \mathrm{nM}$ (data not shown). Although this value is somewhat higher than the value reported by MacKinnon et al. (1988; $K_{d} \sim 3.6 \mathrm{nM}$ ), the difference may result from differences in the $\mathrm{Ca}^{2+}$ concentration of the recording solution ( 1.8 vs $0.3 \mathrm{~mm}$, respectively). These results indicate that CTX sensitivity is most likely determined by amino acid residues located within the constant region, rather than a particular amino or carboxyl domain. Indeed, site-directed mutagenesis experiments using the 4-4 cDNA indicate that an amino acid residue located between the last 2 hydrophobic domains is involved in binding of CTX to $S h \mathrm{~K}^{+}$

Table 1. Time constants of inactivation of 5 transient $S h$ currents

\begin{tabular}{|c|c|c|c|c|c|c|c|c|c|}
\hline \multirow[b]{2}{*}{ cDNA } & \multicolumn{3}{|l|}{$0 \mathrm{mV}$} & \multicolumn{3}{|l|}{$20 \mathrm{mV}$} & \multicolumn{3}{|l|}{$40 \mathrm{mV}$} \\
\hline & $\begin{array}{l}\tau_{1} \\
(\mathrm{msec})\end{array}$ & $\begin{array}{l}\tau_{2} \\
(\mathrm{msec})\end{array}$ & $\frac{A_{1}}{A_{1}+A_{2}}$ & $\begin{array}{l}\tau_{1} \\
(\mathrm{msec})\end{array}$ & $\begin{array}{l}\tau_{2} \\
\text { (msec) }\end{array}$ & $\frac{A_{1}}{A_{1}+A_{2}}$ & $\begin{array}{l}\tau_{1} \\
(\mathrm{msec})\end{array}$ & $\begin{array}{l}\tau_{2} \\
\text { (msec) } \\
\end{array}$ & $\frac{A_{1}}{A_{1}+A_{2}}$ \\
\hline $4-4$ & $\begin{array}{c}5.1 \\
( \pm 1.3)\end{array}$ & - & 1.0 & $\begin{array}{c}3.8 \\
( \pm 0.6)\end{array}$ & - & 1.0 & $\begin{array}{r}3.5 \\
( \pm 0.5)\end{array}$ & - & 1.0 \\
\hline $4-37$ & $\begin{array}{c}10.3 \\
( \pm 2.5)\end{array}$ & - & 1.0 & $\begin{array}{r}5.7 \\
( \pm 2.0)\end{array}$ & $\begin{array}{r}22.0 \\
( \pm 4.2)\end{array}$ & $\begin{array}{c}0.80 \\
( \pm 0.02)\end{array}$ & $\begin{array}{c}4.0 \\
( \pm 0.85)\end{array}$ & $\begin{array}{c}17.5 \\
( \pm 4.9)\end{array}$ & $\begin{array}{c}0.81 \\
( \pm 0.01)\end{array}$ \\
\hline $29-4$ & $\begin{array}{c}13.8 \\
( \pm 3.1)\end{array}$ & $\begin{array}{r}90.5 \\
( \pm 29)\end{array}$ & $\begin{array}{r}0.86 \\
( \pm 0.16)\end{array}$ & $\begin{array}{r}8.6 \\
( \pm 1.3)\end{array}$ & $\begin{array}{c}53.0 \\
( \pm 31)\end{array}$ & $\begin{array}{c}0.77 \\
( \pm 0.02)\end{array}$ & $\begin{array}{r}7.9 \\
( \pm 1.0)\end{array}$ & $\begin{array}{r}34.0 \\
( \pm 14)\end{array}$ & $\begin{array}{c}0.75 \\
( \pm 0.05)\end{array}$ \\
\hline $29-37$ & $\begin{array}{c}7.3 \\
( \pm 2)\end{array}$ & - & 1.0 & $\begin{array}{c}5.9 \\
( \pm 0.94)\end{array}$ & $\begin{array}{c}18.5 \\
( \pm 8.0)\end{array}$ & $\begin{array}{c}0.98 \\
( \pm 0.03)\end{array}$ & $\begin{array}{c}5.4 \\
( \pm 0.74)\end{array}$ & $\begin{array}{c}25.4 \\
( \pm 12)\end{array}$ & $\begin{array}{r}0.94 \\
( \pm 0.03)\end{array}$ \\
\hline $37-37$ & $\begin{array}{l}109 \\
( \pm 5.5)\end{array}$ & - & 1.0 & $\begin{array}{r}80.5 \\
( \pm 12)\end{array}$ & - & 1.0 & $\begin{array}{c}22.4 \\
( \pm 6)\end{array}$ & $\begin{array}{c}68.2 \\
( \pm 5.6)\end{array}$ & $\begin{array}{r}0.22 \\
( \pm 0.09)\end{array}$ \\
\hline $37-4$ & ND & & & ND & & & $\begin{array}{c}6.6 \\
( \pm 1.83)\end{array}$ & - & 1.0 \\
\hline
\end{tabular}

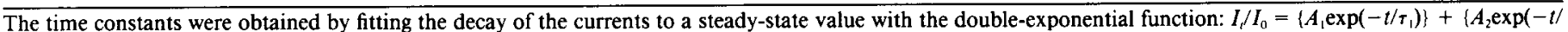

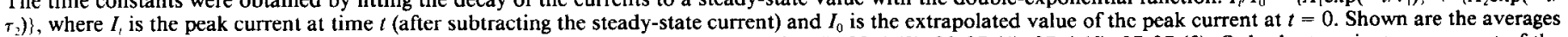

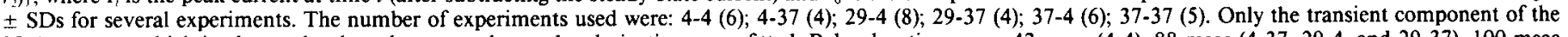

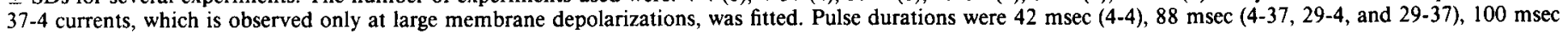
$(37-4)$, and $500 \mathrm{msec}(37-37)$. 


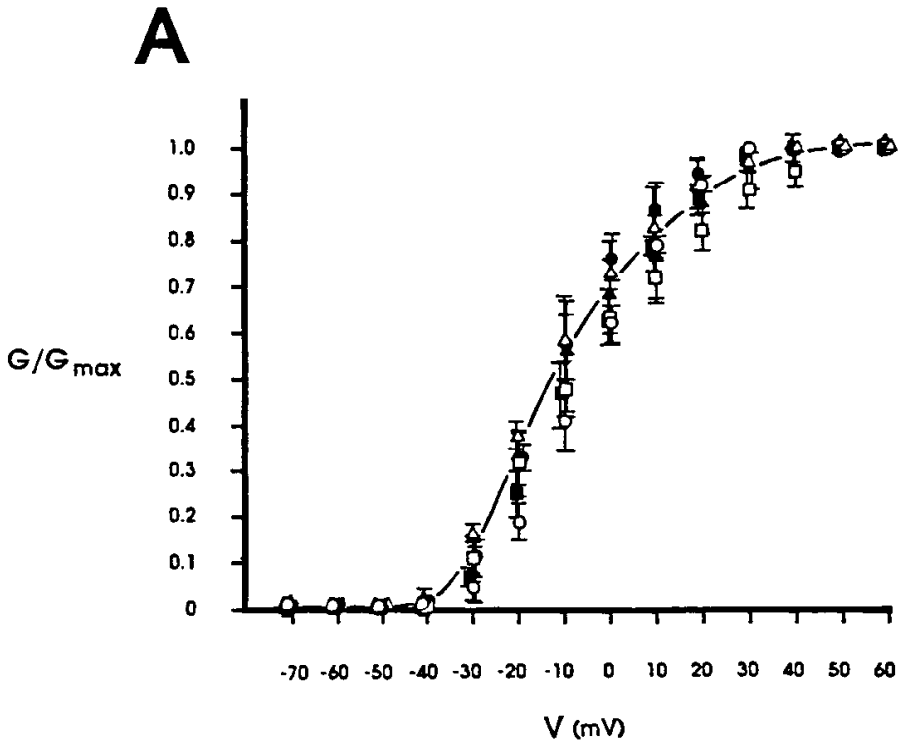

B

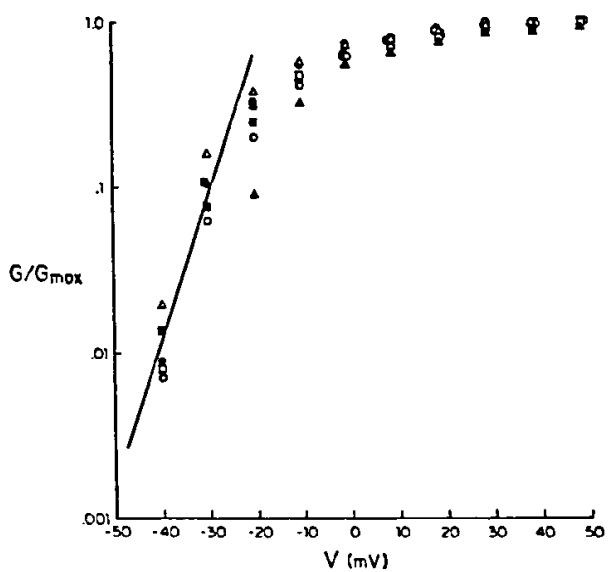

Figure 4. Voltage-dependence of $S h$ currents. A, Relative peak conductance of the $6 S h$ currents shown in Figure 3 plotted as a function of membrane potential. The relative conductance was obtained by dividing the conductance at the indicated potentials by the conductance at +60 $\mathrm{mV}\left(G_{\max }\right)$. The conductance was determined from the equation $G=I / V-V_{\mathrm{K}}$, assuming a $V_{\mathrm{K}}$ of $-80 \mathrm{mV}$. The symbols for each RNA and the number of oocytes used for the average are as follows: $4-4(\square, n=6) ; 29-4(0, n=8) ; 37-4(\Delta, n=5) ; 4-37(\mathbf{\square}, n=4) ; 29-37(\mathbf{Q}, n=4)$; and $37-37(\Delta, n=5)$. The solid curve through the data points was drawn by eye. Error bars are standard deviations. $B$, Semilogarithmic plot of the data shown in $A$ (shown without error bars). The solid line, drawn through those data points giving the maximum change in conductance ( -40 and $-30 \mathrm{mV}$ ), has a slope of $6 \mathrm{mV}$ change in potential for every $e$-fold change in conductance.
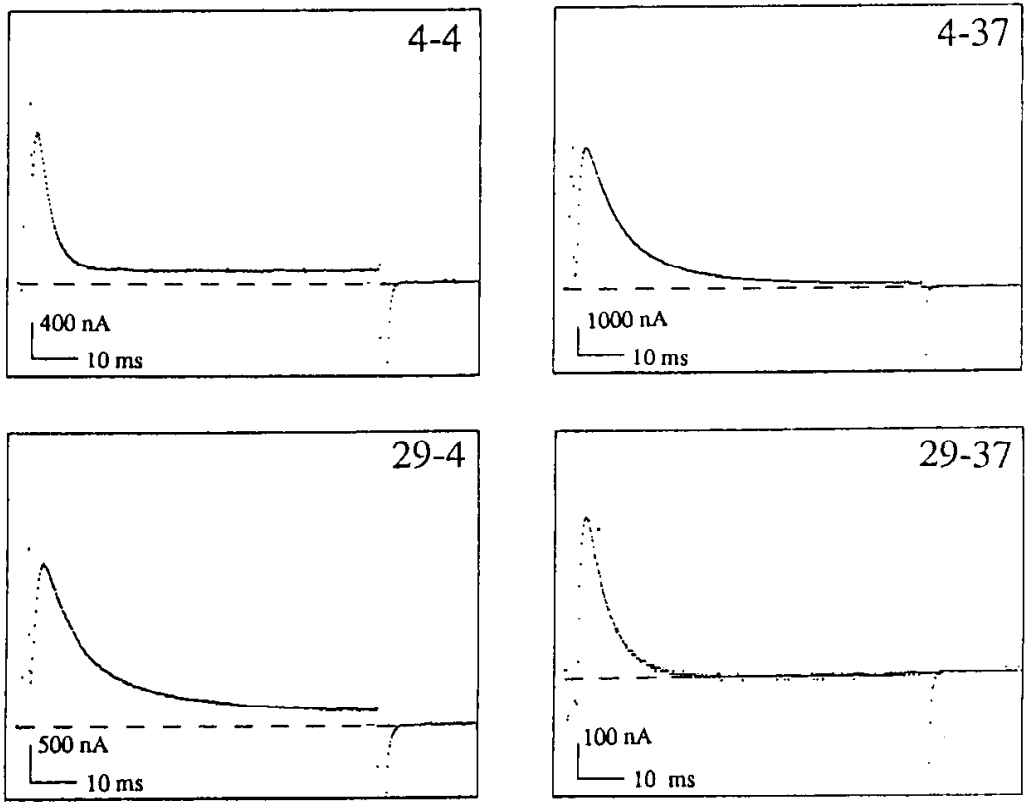

Figure 5. Noninactivating component of $S h$ currents. Oocytes injected with the indicated RNAs were held at $-90 \mathrm{mV}$. The currents obtained during depolarizations to $+30 \mathrm{mV}$, following 1 sec hyperpolarizing pulses to -120 $\mathrm{mV}$, are shown after leak subtraction. Zero current levels are indicated by the broken lines. The fraction of current remaining at the end of the depolarizing pulse was estimated as follows: $4-4$ $(0.091), 29-4(0.125), 37-4(0.88), 4-37$ (0.03), 29-37 (0.01), and 37-37 (0.00).
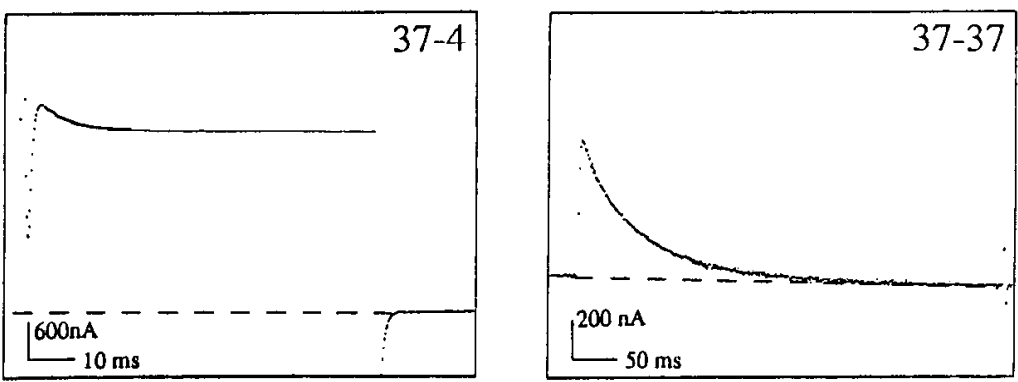


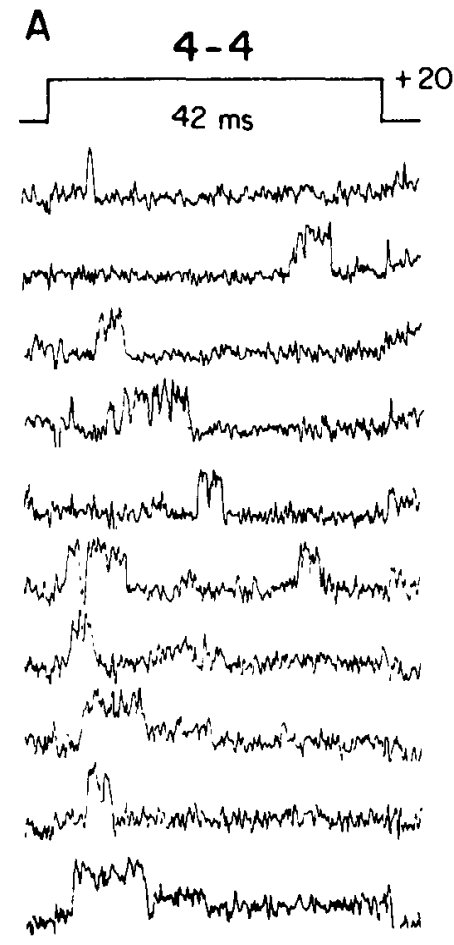

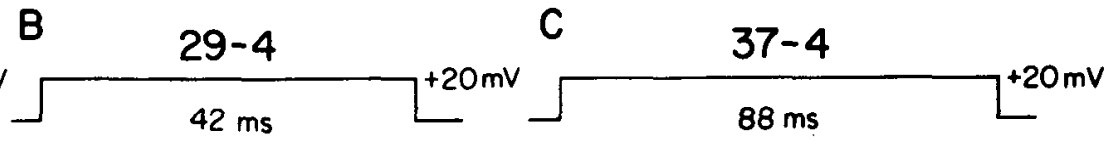
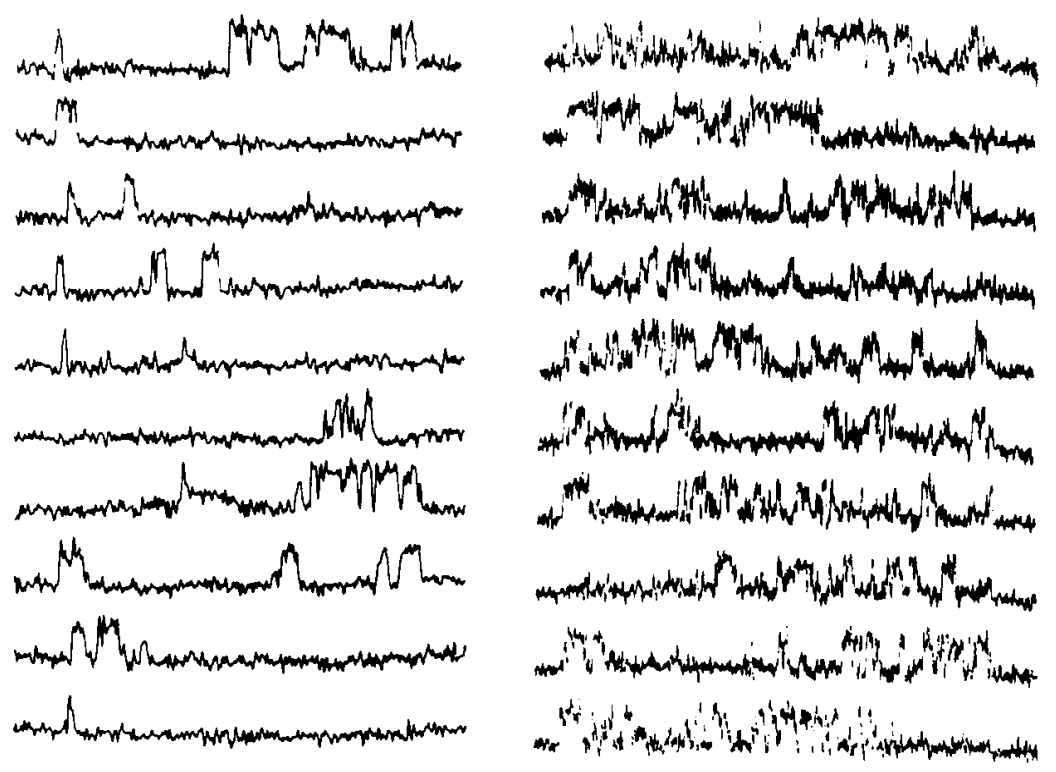

$|\mathrm{pA}|$

Figure 6. Single channels in cell-attached patches from oocytes injected with 4-4 $(A), 29-4(B)$, and 37-4 (C) RNAs. Shown are 10 representative sweeps from each oocyte during depolarizations to $+20 \mathrm{mV}$, from a holding potential of $-100 \mathrm{mV}$. The depolarizing pulse is shown above each set of 10 records. The average of sweeps with no openings was used to subtract leak and uncompensated capacitive currents. Voltage tests were delivered once every $5 \mathrm{sec}$. The currents were low-pass-filtered through an 8 -pole Bessel filter at $2 \mathrm{kHz}$. The data were digitized at $100 \mu \mathrm{sec} /$ point.

channels expressed in oocytes (MacKinnon and Miller, 1989). The differences in CTX sensitivity of Shaker $\mathrm{K}^{+}$channels in oocytes and flies is most likely due to differences in posttranslational modifications. Recent germ-line transformation experiments support this hypothesis since 4-4 channels expressed in Drosophila myocytes are insensitive to blockage by CTX (Zagotta et al., 1989a).

The similarities in $\mathrm{K}^{+}$selectivity and voltage dependence of activation and inactivation of the 6 currents suggests that the channel pore and gating machinery are formed by structures in the constant region of the proteins. Furthermore, similarities in pharmacology of the 6 currents (i.e., sensitivity to 4-AP, TEA, and (TX) suggests that binding sites for these channel blockers must be located within structures formed by the constant region of the proteins.

\section{Variable properties of Shaker $K^{+}$currents}

In contrast to the properties mentioned above, inactivation kinetics of the 6 currents are strongly influenced by the divergent amino and carboxyl domains, suggesting that these regions play an important role in modulating channel inactivation. An analysis of inactivation kinetics of the 6 currents described here can serve as a starting point to generate a kinetic model for inactivation that may account for the observed variations in inactivation kinetics of all $S h$-encoded $\mathrm{K}^{+}$currents.

Time constants for inactivation. The time constants for inactivation onset of the 6 currents were determined by fitting the decline of the current to both single- and double-exponential functions. The values for inactivation time constants at 3 different membrane potentials, and the relative contribution of each time constant, are shown in Table 1. Of the 5 transient currents described here, only the decline of the 4-4 current can be adequately fit to a single-exponential function. The inactivation time course of three of the currents described here (4-4, 4-37, and 29-4) were previously analyzed by Timpe et al. (1988b). In agreement with their results, we find that the decline of the 4-37 and 29-4 currents cannot be fit by a single-exponential function without showing noticeable deviations at large membrane depolarizations. In addition to these 2 currents, we also find that the decline of the 29-37 and 37-37 currents are not adequately fit by single-exponential functions at large membrane depolarizations, and all 4 currents can be adequately fit by double-exponential functions. The decline of the small, transient component of 37-4 currents, present only at large membrane depolarizations, was fit to a single exponential.

Incomplete inactivation. The currents expressed from different $S h$ RNAs differ in the relative amount of the steady-state component $\left(I_{\mathrm{ss}} / I_{\mathrm{peak}}\right)$ remaining at the end of the depolarizing pulse. Figure 5 shows the 6 currents recorded in oocytes at membrane potentials of $+30 \mathrm{mV}$, after leak subtraction. The steady-state component is negligible for all channels containing a type 37 carboxyl domain (4-37: $0.03 \pm 0.015, n=4 ; 29-37$ : $0.02 \pm 0.008, n=3$ and 37-37:0.01 $\pm 0.005, n=4)$. In contrast, channels containing type 4 carboxyl domains (4-4, 29-4, and 37-4) exhibit relatively large steady-state components at the end of the test pulse. In these channels, the relative amount of the 

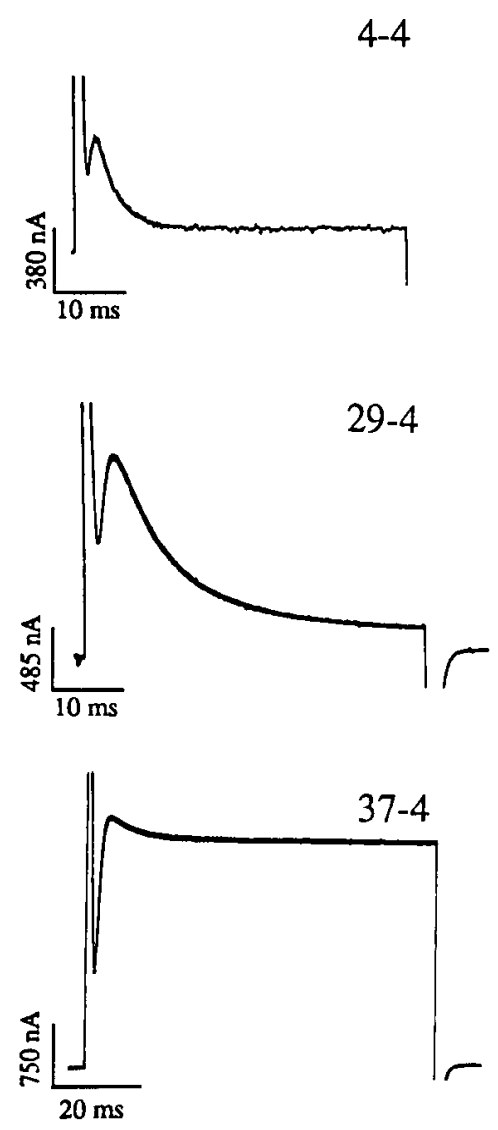
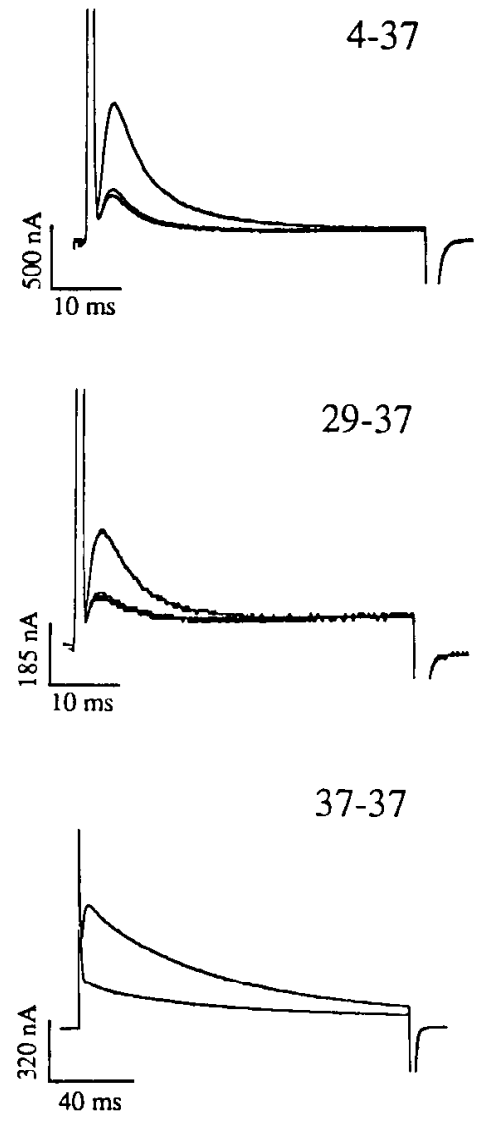

Figure 7. Recovery from inactivation of $S h$ currents. Oocyges injected with the indicated RNAs were given 3 depolarizing pulses of the indicated duration to $+30 \mathrm{mV}$ at a frequency of once every $1 \mathrm{sec}$. The membrane potential was held at $-100 \mathrm{mV}$ between depolarizations. Current records are shown without leak subtraction.

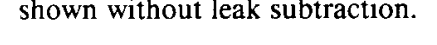

(1)

steady-state current varies with the amino domain. The average values obtained from several different oocytes are $0.09( \pm 0.03$, $n=5)$ for $4-4$ currents, $0.14( \pm 0.05, n=6)$ for $29-4$ currents and $0.89( \pm 0.04, n=4)$ for $37-4$ currents.

Single-channel records of oocytes injected with 4-4 RNA (Iverson et al., 1988; Zagotta et al., 1989b) occasionally show more than one open burst per depolarization, indicating that these channels can reopen after they inactivate. Channel reopening following inactivation is the most plausible explanation for the steady-state component of the current observed in the macroscopic current records and indicates the presence of an inactivated state that is reversible at depolarizing potentials (a non-absorbing inactivated state). Although this feature of channel reopening from the inactivated state during depolarizations is unlike that which has been observed for $\mathrm{Na}^{+}$channels (Armstrong and Bczanilla, 1977; Aldrich et al., 1983; Aldrich and Stevens, 1987), it is common for several types of $\mathrm{K}^{+}$channels (e.g., Hoshi and Aldrich, 1988; Solc and Aldrich, 1988).

We find that for those channels containing a type 4 carboxyl domain the relative amount of steady-state current depends on the amino domain with $37-4 \gg 29-4>4-4$. One prediction consistent with this result is that the probability of channel reopening is influenced by the amino domain. Indeed, Zagotta et al. (1989b) have shown that 29-4 single channels show both more opening bursts per trace as well as more traces with 2 or more bursts than do oocytes expressing 4-4 RNA. This indicates that the probability of channel reopening during depolarization is greater for 29-4 channels than 4-4 channels. Given the fact that the relative amount of steady-state current in oocytes ex- pressing 37-4 channels is much larger than that in oocytes expressing 29-4 channels, we would expect 37-4 channels to show an even higher frequency of channel reopening. Single-channel recordings of oocytes injected with 37-4 RNA confirm this hypothesis (Fig. 6). Channel reopening from inactivation appears to be the main difference between single-channel records of channels containing each of the 3 different amino domains in combination with a type 4 carboxyl domain. Channel reopening is infrequent for 4-4 channels (Fig. 6A), intermediate for 29-4 channels (Fig. 6B), and extremely frequent for $37-4$ channels (Fig. 6C). The channels also differ in their mean open durations. Mean open durations, obtained by fitting open time distributions with a single exponential, were as follows: $0.8 \pm 0.1 \mathrm{msec}$, $n=2$ for $4-4$ channels; $1.05 \pm 0.15 \mathrm{msec}, n=4$ for $29-4$ channels; and $1.5 \pm 0.2 \mathrm{msec}, n=3$ for $37-4$ channels. In contrast, all 3 channels have a similar single-channel conductance of 9-11 pS.

Our value for the relative amount of the steady-state component of the 4-4 current is significantly smaller than the value of 0.21 reported by Timpe et al. (1988b). This is probably the result of the difference in temperature at which the experiments were carried out $\left(20-22^{\circ} \mathrm{C}\right.$ for the experiments reported here and $12^{\circ} \mathrm{C}$ for the experiments reported by Timpe et al., 1988b). Indeed, a temperature dependence of the relative steady-state component is obvious in the traces shown in figure 1 of Iverson et al. (1988), suggesting that the rates of the different reactions that determine macroscopic inactivation kinetics may have different temperature coefficients.

Recovery from inactivation. The 6 currents are noticeably dif- 
A

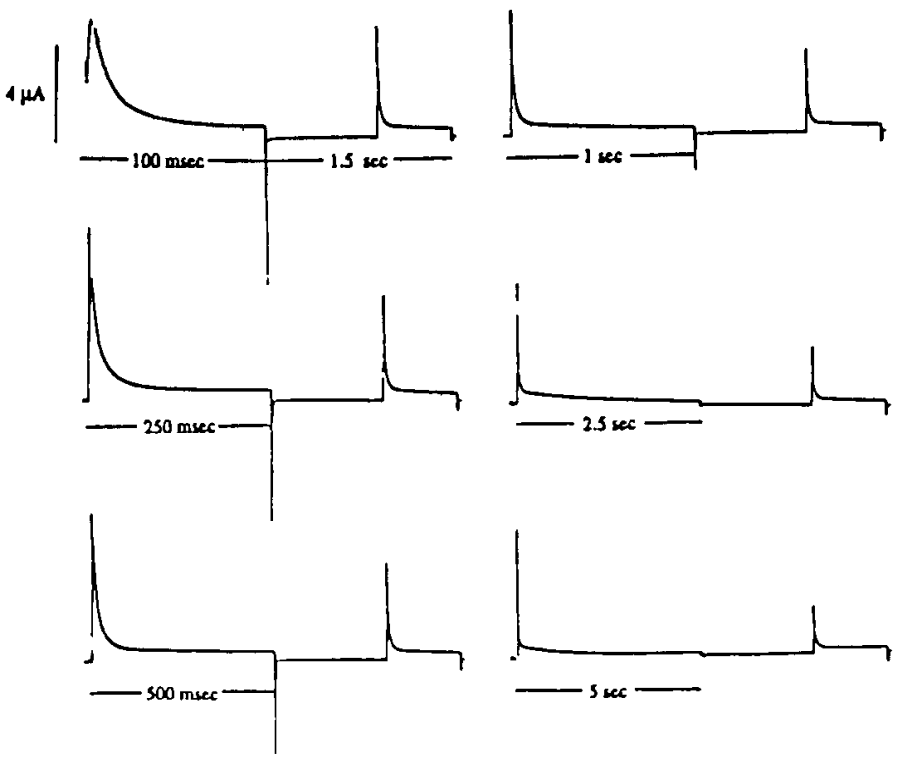

B

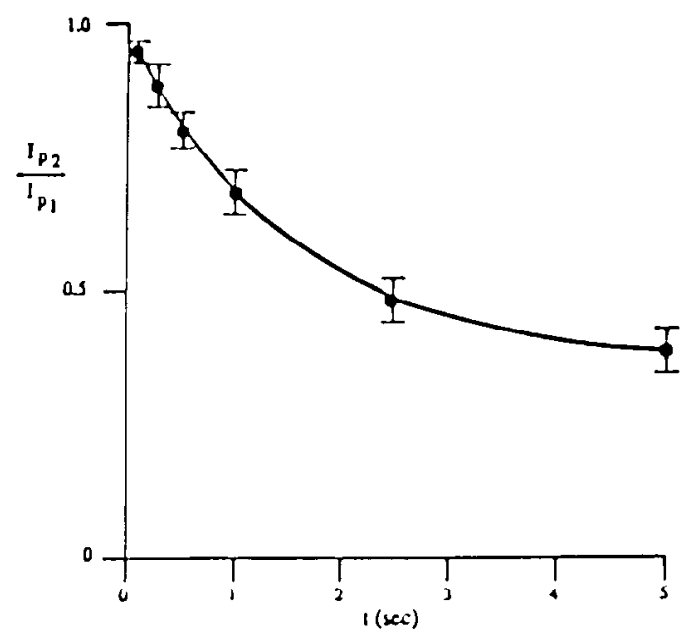

C

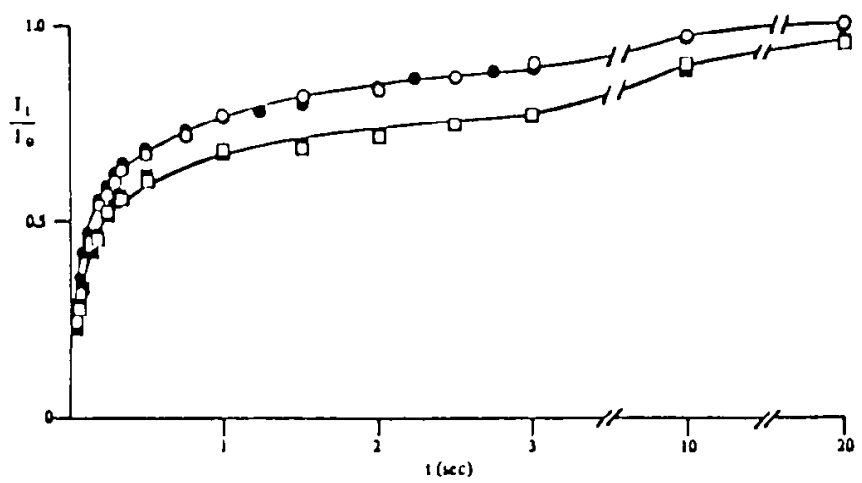

Figure 8. Slow inactivation of 29-4 $S h \mathrm{~K}^{+}$currents. $A$, An oocyte expressing 29-4 RNA was depolarized to $+30 \mathrm{mV}$ for varying durations, held at $-100 \mathrm{mV}$ for $1 \mathrm{sec}$, then depolarized a second time to $+30 \mathrm{mV}$ for $500 \mathrm{msec}$. Currents obtained during this pulse paradigm are shown for 6 different durations of the first test pulse. The oocytc was held at $-100 \mathrm{mV}$ for at least $3 \mathrm{~min}$ prior to the next series. $B$, Ratio of the peak current obtained during the second depolarization $\left(I_{p 2}\right)$ to the peak ferent in the rate at which they recover from inactivation. This result is illustrated by the frequency response experiments shown in Figure 7. In those oocytes expressing RNA with a type $43^{\prime}$ domain $(4-4,29-4$, or $37-4)$, the current magnitude is not significantly reduced by successive depolarizations to $+30 \mathrm{mV}$ separated by $1 \mathrm{sec}$ intervals at $100 \mathrm{mV}$, indicating that these channels recover completely from inactivation under these conditions. In contrast, in those oocytes expressing RNA with a type $373^{\prime}$ domain (4-37, 29-37, and 37-37), peak current amplitudes obtained during the second depolarization are about $30 \%$ that obtained during the first depolarization, indicating that the $1 \mathrm{sec}$ interval at $-100 \mathrm{mV}$ is not sufficient to allow for complete recovery from inactivation of these channels.

The slow recovery from inactivation of those channels containing a type 37 carboxyl domain may reflect slower reaction rates for recovery from the same inactivated state as that entered by channels containing a type 4 carboxyl domain. Alternatively, channels containing the type 37 carboxyl domain may enter, more readily, a different inactivated state from which recovery is slow. Sodium channels of Myxicola giant axons are characterized by inactivating quickly into a state from which recovery is very slow (Rudy, 1976, 1981). Sodium channels of other cell types also enter this inactivated state, but only after prolonged depolarizations (Rudy, 1976, 1978). We therefore asked if $S h$ $\mathrm{K}^{+}$channels containing type 4 carboxyl domains would exhibit slow recovery from inactivation after prolonged depolarizations. The results obtained from oocytes injected with 29-4 RNA are shown in Figure 8. Currents were recorded in oocytes given depolarizing pulses to $+30 \mathrm{mV}$ of increasing duration $\left(I_{1}\right)$, followed by a $1 \mathrm{sec}$ interval at $-100 \mathrm{mV}$ and a second depolarization to $+30 \mathrm{mV}\left(I_{2}\right)$. Figure $8 \mathrm{~A}$ shows the traces obtained from one experiment. Figure $8 B$ shows the fraction of the current that has recovered from inactivation $\left(I_{2} / I_{1}\right)$ during the $1 \mathrm{sec}$ interval at $-100 \mathrm{mV}$, plotted as a function of the duration of the first depolarizing pulse. The fraction of the current that recovers from inactivation decreases as the duration of the first depolarization increases. Greater than $60 \%$ of the current does not recover from inactivation during the 1 sec interval when the duration of the initial depolarization is $5 \mathrm{sec}$.

The relative amount of steady-state current remaining at the end of short depolarizing pulses is about $15 \%$ for the $29-4$ channels (see Fig. 5). Longer depolarizations result in a further decrease in the steady-state current (Fig. $8 \mathrm{~A}$ ). However, the fraction of the current that recovers slowly from inactivation is much larger (60\% after a $5 \mathrm{sec}$ depolarization) than the proportion of steady-state current. This indicates that most chan-

current obtained during the first depolarization $\left(I_{p 1}\right)$ plotted as a function of duration of the first depolarization. The data were obtained from 3 separate experiments similar to the one shown in $A$. Error bars are standard deviations. $C$, Recovery from slow inactivation at -100 and $-80 \mathrm{mV}$. The oocytes were depolarized to $+30 \mathrm{mV}$ for $1 \mathrm{sec}$, held at -100 or $-80 \mathrm{mV}$ for varying durations, then depolarized again to +30 $\mathrm{mV}$ for $100 \mathrm{msec}$. Between test pulses the membrane was held at -100 $\mathrm{mV}$ for at least $1 \mathrm{~min}$. The data are shown as the ratio of the peak current obtained during the second depolarization $\left(I_{t}\right)$ to the peak current obtained during the first depolarization $\left(I_{0}\right)$, plotted as a function of the duration of the interval at -100 ( $\odot$ and $O$ ) or $-80 \mathrm{mV}(\square$ and $\square$ ). The curves were fitted to a 3-exponential function using Asystant (McMillan). The time constants and the contribution of each time constant are as follows: $20 \mathrm{msec}(0.27), 160 \mathrm{msec}(0.36)$, and $2640 \mathrm{msec}(0.37)$ for the data obtained at $-100 \mathrm{mV}$, and $70 \mathrm{msec}(0.35), 300 \mathrm{msec}(0.27)$, and $6800 \mathrm{msec}(0.38)$ for the data obtained at $-80 \mathrm{mV}$. 
nels that enter the inactivated state from which recovery is very slow, do so by passing through the first inactivated state. A value of $2.15 \mathrm{sec}$ was calculated, from the curve shown in Figure $8 B$, for the time constant for onset of the slow inactivation of the $29-4$ current at $+30 \mathrm{mV}$. Figure $8 \mathrm{C}$ shows the time course of recovery from inactivation of the $29-4$ channels at -100 and $-80 \mathrm{mV}$ following a $1 \mathrm{sec}$ depolarization. Approximately $40 \%$ of the current recovers extremely slowly with time constants of $2.64 \mathrm{sec}$ at $-100 \mathrm{mV}$ and $6.8 \mathrm{sec}$ at $-80 \mathrm{mV}$. These values are comparable to the main time constants for recovery of the 4-37 and $37-37$ currents $(3.11 \mathrm{sec}$ at $-100 \mathrm{mV}$ and $8.1 \mathrm{sec}$ at -80 $\mathrm{mV}$ for 4-37 and $1.9 \mathrm{sec}$ at $-100 \mathrm{mV}$ for 37-37).

The analysis shown in Figure 8 demonstrates that $S h$ channels containing a type 4 carboxyl domain can also enter an inactivated state from which recovery during hyperpolarization is very slow. Although our data do not prove conclusively that this state is the same as that entered by channels with type 37 carboxyl domains, it is consistent with the hypothesis that channels containing type 37 carboxyl domains enter such a state much more readily than do channels containing type 4 carboxyl domains.

Quantitative analysis of recovery from inactivation in double pulse experiments reveals that inactivation recovery of $S h$ channels takes place with complex kinetics (Iverson et al., 1988; Timpe et al., 1988b). Time constants for recovery from inactivation at $-100 \mathrm{mV}$ for 4 of the currents shown here were obtained by fitting the recovery time course after a $100 \mathrm{msec}$ depolarization to a doublc-cxponcntial function (Tablc 2). Although small differences in the recovery time constants are observed for those channels containing identical carboxyl domains but different amino domains (e.g., 4-4 vs $29-4$ or 4-37 vs 3737 ), these differences are insignificant compared to the large differences in recovery rates among those oocytes expressing channels with the identical amino domain but different carboxyl domains (e.g., 4-4 vs. 4-37). However, the results shown in Figure 8 suggest that caution should be used in quantitative comparisons of recovery from inactivation of the various $S h$ channels since the recovery time course for a given channel can be influenced by the duration of the inactivating pulse. Thus, the small differences in recovery from inactivation of channels containing the same carboxyl domain may reflect differences in the equilibrium between different inactivated states, as well as differences in the rates of a particular recovery reaction.

\section{Discussion}

Extent of diversity of $\mathrm{Sh}$ encoded $K^{+}$channels

The results of the experiments presented here indicate that $S h$ RNAs can direct the expression of at least 6 functionally distinct $\mathrm{K}^{+}$currents in Xenopus oocytes (including one "noninactivating" current) and, thus, extends the previously reported $\mathrm{K}^{+}$ channel diversity potentially encoded by the $S h$ gene. The diversity of $S h \mathrm{~K}^{+}$channels is dominated by properties of channel kinetics (in particular, inactivation kinetics) rather than voltage dependence, pharmacology, or $\mathrm{K}^{+}$selectivity. Although the divergent amino and carboxyl domains are the primary determinants of the kinetic variability of $\mathrm{K}^{+}$channels encoded at the $S h$ locus, it is unlikely that these sequences are the sole determinants of channel kinetics. Indeed, alterations of amino acid residues within the constant region have been shown to modify inactivation kinetics (McCormack et al., 1989, 1990a). Although these mutants will prove useful in determining structurefunction relations of $\mathrm{K}^{+}$channels, they provide no insight into
Table 2. Recovery from inactivation of $4 S h$ currents

\begin{tabular}{clll} 
cDNA & $\begin{array}{l}\tau_{1} \\
(\mathrm{msec})\end{array}$ & $\begin{array}{l}\tau_{2} \\
(\mathrm{mscc})\end{array}$ & $\frac{A_{1}}{A_{1}+A_{2}}$ \\
\hline $4-4$ & $15 \pm 9$ & $476 \pm 72$ & 0.82 \\
$29-4$ & $22 \pm 7$ & $325 \pm 121$ & 0.46 \\
$4-37$ & $3.11 \times 10^{3} \pm 830$ & $32 \times 10^{3} \pm 7 \times 10^{3}$ & 0.84 \\
$37-37$ & $1.9 \times 10^{3} \pm 720$ & $46 \times 10^{3} \pm 4 \times 10^{3}$ & 0.79
\end{tabular}

Recovery from inactivation was determined by measuring the peak current during a second depolarizing step to $+30 \mathrm{mV}\left(I_{2}\right)$ following a depolarizing step to the same voltage, separated by a recovery interval at $-100 \mathrm{mV}$ of duration, $t$. The time constants for recovery from inactivation were obtained by fitting the data to the equation $I_{2} / I_{1}=1-\left\{A_{1} \exp \left(-t / \tau_{1}\right)\right\}-\left\{A_{2} \exp \left(-t / \tau_{2}\right)\right\}$, where $I_{1}$ is the peak current during the first depolarizing pulse and $A_{1}+A_{2}=1$.

the extent, or the source, of the naturally occurring diversity of channels encoded at $S h$.

It remains to be determined whether all 6 of the RNAs expressing $\mathrm{K}^{\prime}$ channels in oocytes represent bonafide transcripts of the $S h$ locus. If the $5^{\prime}$ and $3^{\prime}$ domains assort independently, then it is possible that both 29-37 and 37-4 cDNAs represent normal $S h$ transcripts, even though they were never isolated from Drosophila cDNA libraries. That $S h$ may encode a nontransient $\mathrm{K}^{+}$current is in apparent conflict with experimental results suggesting that $S h$ RNAs encode only transient $\mathrm{K}^{+}$currents in Drosophila (Salkoff and Wyman, 1983; Wu and Haugland, 1985; Solc et al., 1987). Furthermore, although nontransient $\mathrm{K}^{+}$currents have been identificd in Drosophila (Salkoff and Wyman, 1983; Wu and Haugland, 1985; Solc et al., 1987; Byerly and Leung, 1988; Zagotta et al., 1988), none is affected by any of the $S h$ mutations, including one in which the genomic region encoding the entire constant region of the gene has been deleted (R. Aldrich, personal communication). It is possible that 37-4 channels may be expressed only in cell types or on neuronal processes that have not yet been examined electrophysiologically. Regardless of whether this chimera represents a normal $S h$ transcript, the analysis of 37-4 currents in oocytes is useful in understanding the role of the divergent amino and carboxyl domains in $S h \mathrm{~K}^{+}$channel inactivation.

The fact that all 3 RNAs containing a type $293^{\prime}$ domain (429, 29-29, and 37-29) do not express $\mathrm{K}^{+}$channels in oocytes suggests that this particular $3^{\prime}$ domain may not represent a mature transcript of the $S h$ locus. This assumption is strengthened by the following facts: (1) cDNAs containing the type $293^{\prime}$ domain have been isolated in combination with only a single $5^{\prime}$ domain (H29 or 29-29, Kamb et al., 1988); (2) the type 29 3 ' domain appears to be encoded by a genomic region immediately following a splice donor site (Schwarz et al., 1988); and (3) DNA sequence and restriction analyses of a number of $S h$ cDNAs indicate that at least some of these may have arisen from incompletely processed RNAs (Kamb et al., 1987, 1988). This raises the possibility that the H29 cDNA may have been generated from an incompletely processed $S h$ transcript.

\section{Sh channels in Xenopus oocytes vs Drosophila}

The evidence suggests that the $\mathrm{K}^{+}$channels expressed in oocytes injected with a single $S h$ RNA are homomultimers of $S h$ gene products (Iverson et al., 1988; Timpe et al., 1988b). Since current kinetics does not depend on the total current magnitude or the amount of injected RNA, then it is likely that a homomultimer of a single aggregation number is responsible for each channel type and that each of the currents shown here reflects 
a single population of identical channels. This is particularly important when considering the 37-4 current, where one might be tempted to assumc that the transient and the steady-state components reflect the contribution of 2 distinct channel types.

Several differences have been observed between $S h$ channels expressed in oocytes and those expressed in Drosophila (MacKinnon et al., 1988; MacKinnon and Miller, 1989; Zagotta et al., 1989a, b). One major difference is the extremely slow rate of recovery from inactivation of all currents expressed from RNAs containing a type $373^{\prime}$ domain $(4-37,29-37$, and 37-37; Fig. 7 and Table 2). It is possible that these channels are expressed only in cell types or cellular regions that have not yet been examined electrophysiologically. Alternatively, these $S h$ gene products may only be expressed in combination with the other $S h$ gene products. If channels exhibiting the slow recovery from inactivation characteristic of these channels are expressed in the fly, this will result in interesting physiological properties. The slow recovery from inactivation suggests that even brief depolarizations will produce cumulative inactivation which will lead to relatively long lasting increases in neuronal excitability. Thus, these channels could mediate changes in the level of excitability induced by neurotransmitters without the intervention of second messengers. The observed differences between $S h \mathrm{~K}^{+}$ channels expressed in oocytes and those expressed in the fly may arise from (1) the generation of heteromultimers composed of more than one Sh gene product (Haugland and Wu, 1986, 1990; Haugland, 1987; McCormack et al., 1990b); (2) the interaction of Sh gene products with the products of other Drosophila genes; (3) posttranslational modifications; or (4) different membrane environments.

\section{Role of the amino and carboxyl domains in Sh $K^{+}$channel inactivation kinetics}

Striking differences in the amount of steady-state current remaining at the end of the depolarizing pulse (Fig. 5) are observed in channels containing type 4 carboxyl domains but different amino domains. Single-channel studies indicate that differences in the amount of steady-state current result from differences in the frequency of channel reopening from inactivation (Fig. 6). Furthermore, there appears to be an inverse relationship between channel reopening frequency and the macroscopic rates of inactivation (Table 1) or rates of single-channel closure (i.e., inverse of the mean open durations). These results are consistent with a model in which the divergent aminn domains influence the stability of the inactivated state; the type 4 amino domain produces the most stable inactivation, 29 is intermediate, and 37 is the least stable. Consistent with the model that the amino domain is the primary determinant of inactivation of open channels, Hoshi et al. (1989) find that deletions and point mutations in this region remove channel inactivation.

Currents expressed in oocytes injected with RNAs containing type $373^{\prime}$ domains are characterized by both their negligible steady-state components and their extremely slow recovery from inactivation. We suggest that both of these properties arise from the relatively rapid entrance of these channels into a second inactivated state. If this second inactivated state is much less reversible at depolarizing potentials than the first inactivated state, that is, if it acts as an absorbing inactivatcd statc, this would account for the much smaller steady-state current in those oocytes expressing channels with type 37 carboxyl domains. Similarly, if recovery from inactivation during hyperpolarization proceeds much faster for channels in the first inactivated state than for channels in the second inactivated state, this would also explain the extremely slow time course for recovery from inactivation, which occurs during short depolarizations, of those channels containing type 37 carboxyl domains.

The experiments shown in Figure 8 suggest that channels containing type 4 carboxyl domains also enter a similar inactivated state (from which recovery proceeds very slowly), but only after prolonged depolarizations. Several independent results support the view that channels containing type 4 carboxyl domains can enter more than one inactivated state: (1) several of the $S h$ currents inactivate with more than one exponential (Timpe et al., 1988b; see also Table 1), and (2) in single-channel studies of Drosophila embryonic myocytes, although multiple bursts may be observed during relatively short depolarizing steps, the channels eventually inactivate during maintained depolarizations (Zagotta and Aldrich, 1990). We suggest that the role of the divergent carboxyl domains is to influence the relative stability between the first $\left(I_{1}\right)$ and the second $\left(I_{2}\right)$ inactivated states.

\section{A kinetic model for Sh $\mathrm{K}^{+}$channel inactivation}

Although further single-channel analyses will be extremely useful in examining and refining the ideas presented here, we have tested whether a kinetic model consistent with these ideas can reproduce all of the kinetic properties of the 6 currents observed during step depolarizations. As a basis for our model we have adapted a kinetic scheme for $S h$ A-type $\mathrm{K}^{+}$channels recently proposed by Zagotta and Aldrich (1990) and used, by them, to fit the results of single-channel studies of Al channels in Drosophila embryonic myocytes. According to their scheme, during depolarizations, the channel traverses 5 closed states before entering a single open state and then inactivates:

$$
\mathrm{C}_{1} \underset{\beta}{\stackrel{4 \alpha}{\rightleftarrows}} \mathrm{C}_{2} \underset{2 \beta}{\stackrel{3 \alpha}{\rightleftarrows}} \mathrm{C}_{3} \underset{3 \beta}{\stackrel{2 \alpha}{\rightleftarrows}} \mathrm{C}_{4} \underset{4 \beta}{\stackrel{\alpha}{\rightleftarrows}} \mathrm{C}_{3} \underset{100}{\stackrel{3800}{\rightleftarrows}} \mathrm{O} \underset{10}{\stackrel{400}{\rightleftarrows}} \mathrm{I}
$$

where $\alpha=700 e^{(1 / 27)}$ and $\beta=287 e^{-\left(r^{1 / 18}\right)}$. Zagotta and Aldrich (1990) propose that only the first 4 opening reactions (from $\mathrm{Cl}$ to $\mathrm{C5}$ ) are voltage dependent. Neither the final opening reaction (from $\mathrm{C} 5$ to $\mathrm{O}$ ), nor the inactivation reaction (from $\mathrm{O}$ to I) have any voltage dependence. They have assigned rate constants for these reactions and have also suggested that the inactivated state is readily reversible during depolarization.

Because of the similarity of the voltage-dependent and activation properties of the various $S h$ currents expressed in oocytes, and those expressed in Drosophila muscle, we have adapted their scheme to simulate the 6 currents studied here, but have explicitly included a second inactivated state $\left(I_{2}\right)$ :

$$
\mathrm{C}_{1} \underset{\beta}{\stackrel{4 \alpha}{\rightleftarrows}} \mathrm{C}_{2} \underset{2 \beta}{\stackrel{3 \alpha}{\rightleftarrows}} \mathrm{C}_{3} \underset{3 \beta}{\stackrel{2 \alpha}{\rightleftarrows}} \mathrm{C}_{4} \underset{4 \beta}{\stackrel{\alpha}{\rightleftarrows}} \mathrm{C}_{5} \underset{700}{\stackrel{2000}{\rightleftarrows}} \mathrm{O} \underset{k_{1}}{\stackrel{k_{1}}{\rightleftarrows}} \mathrm{I}_{1} \underset{k_{2}}{\stackrel{k_{2}}{\rightleftarrows}} \mathrm{I}_{2}
$$

The rate constants for the voltage-dependent transitions were taken from Zagotta and Aldrich (1990). However, in order to fit their model to our currents it was necessary to shift the voltage-dependent reactions by $7 \mathrm{mV}$ in the depolarizing direction. In addition, we have not included the closed state inactivation that was part of the scheme proposed by Zagotta and Aldrich (1990) because it is negligible at most of the membrane potentials used in our simulations. Furthermore, because our 
currents peak somewhat more slowly than those predicted from their model, it was also necessary to change the rate constant for the opening reaction $(\mathrm{C} 5-\mathrm{O})$. We have also adjusted the values for the $\mathrm{O}-\mathrm{C} 5$ and $k_{1}$ rate constants in order to obtain mean open durations similar to those observed experimentally (Fig. 6). Although it is entirely possible that the rate constants for the $\mathrm{C} 5-\mathrm{O}$ transition may also be influenced by the amino and/or carboxyl domains, we have chosen to use fixed values for this reaction in order to reduce the number of free parameters in the fit. Using these values we then searched for combinations of rate constants for the inactivation reactions $\left(k_{-1}, k_{2}, k_{-2}\right)$ that best simulated the 6 different currents described here.

The results of the best simulation for all 6 currents are shown in Figure 9, and the values of the rate constants used for the simulations are shown in Table 3. The following patterns for the rate constants emerge: (1) the rate of constant for the forward reaction from $\mathrm{O}$ to $\mathrm{I}_{1}\left(k_{1}\right)$ is determined by the amino domain with $4>29>37,(2)$ the rate constant for the reverse reaction, from $I_{1}$ to $O\left(k_{-1}\right)$ is determined by both the amino and the carboxyl domains with $37>29>4$ for the amino domain, and $37>4$ for the carboxyl domain. However, the influence of the amino domain predominates, (3) the rate constants for the forward $\left(k_{2}\right)$ and reverse $\left(k_{-2}\right)$ reactions between $I_{1}$ and $I_{2}$ are determined primarily by the carboxyl domains, with $37 \gg 4$ for the forward rate constant $\left(k_{2}\right)$, and $4 \gg 37$ for the reverse rate constant $\left(k_{-2}\right)$. This pattern is consistent with a model in which the variable amino domains determine the stability of the first inactivated state $\left(I_{1}\right)$, while the variable carboxyl domains influence the relative stability between the first $\left(I_{1}\right)$ and the second $\left(\mathrm{I}_{2}\right)$ inactivated states.

Table 3 also shows the values obtained from the simulated currents of the macroscopic time constants for inactivation and the ratios of steady state to peak current at the end of a depolarizing pulse. The derived values are similar to those obtained experimentally. According to the model, in those channels containing type 4 and type 29 amino domains (4-4, 4-37, 29-4, and 29-37), the macroscopic time constants for inactivation onset are influenced primarily by the amino domains. In these channels, the different carboxyl domains affect macroscopic inactivation somewhat, as a result of their effects on the reverse re-

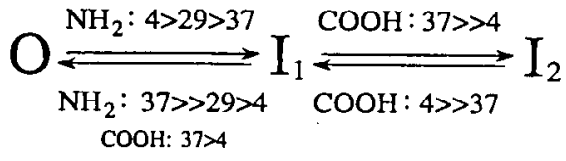

4-4

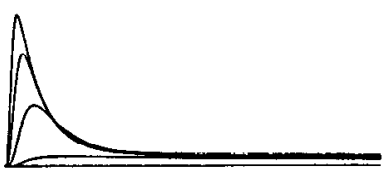

$29-4$

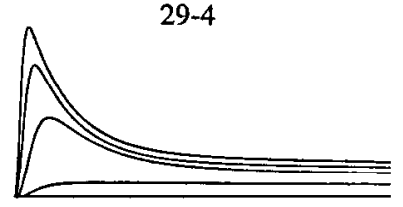

$37-4$

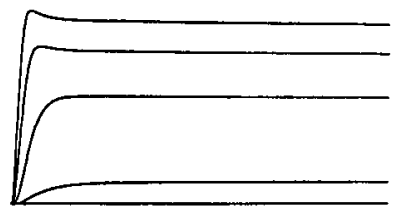

$4-37$

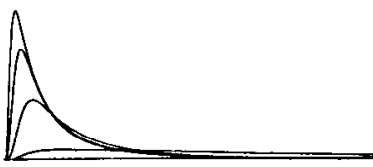

29-37

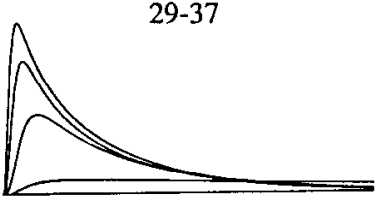

$37-37$

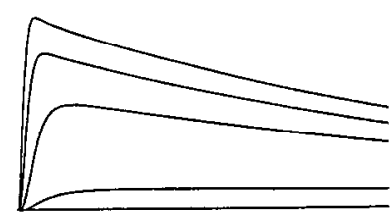

Figure 9. Simulation of the $6 S h$ currents shown in Figure 2. The currents were obtained from numerical solutions of the model utilizing the rate constants described in the text and in Table 3. Shown here are the superimposed, simulated currents obtained during $50 \mathrm{msec}$ depolarizations to $-40,-20,0,20$, and $+40 \mathrm{mV}$ for each of the $S h$ channels.

action between the first inactivated state $\left(I_{1}\right)$ and the open state, and the reaction between the first $\left(I_{1}\right)$ and second $\left(I_{2}\right)$ inactivated states. The latter reaction (between $I_{1}$ and $I_{2}$ ) is largely responsible for the slower component of inactivation that is particularly prominent in 4-37 and 29-37 channels. For those channels containing the type 37 amino domain (37-4 and 37-37), the time course of the macroscopic currents during a depolarizing pulse is determined by both the amino and carboxyl domains. In the

Table 3. Simulation of $6 \mathrm{Sh} \mathrm{K}^{+}$currents

\begin{tabular}{lcccccc} 
& \multicolumn{7}{c}{ cDNA } \\
\cline { 2 - 7 } & $4-4$ & $29-4$ & $37-4$ & $4-37$ & $29-37$ & $37-37$ \\
\hline Rate constants $^{a}\left(\mathrm{sec}^{-1}\right)$ & & & & & & \\
$\quad k_{1}$ & 400 & 200 & 100 & 400 & 200 & 100 \\
$k_{-1}$ & 15 & 35 & 500 & 30 & 60 & 600 \\
$k_{2}$ & 5 & 5 & 5 & 150 & 150 & 150 \\
$k_{-2}$ & 4 & 4 & 4 & 0 & 0 & 0 \\
$\tau$ inactivation $^{b}(\mathrm{at}+40 \mathrm{mV})$ & & & & & & \\
$\tau_{1}(\mathrm{msec})$ & 3.2 & 6.1 & 3.0 & 3.4 & 7.9 & 20 \\
$\tau_{2}$ (msec) & 7.8 & 14 & - & 11 & 56 & 60 \\
$A_{1} /\left(A_{1}+A_{2}\right)$ & 0.90 & 0.79 & 1.0 & 0.85 & 0.90 & 0.2 \\
$I_{\text {ss }} / I_{\text {peak }}(\mathrm{at}+40 \mathrm{mV})$ & 0.06 & 0.18 & 0.91 & 0 & 0.2 & 0.1 \\
\hline
\end{tabular}

${ }^{a}$ Rate constants of the inactivation reactions for the model described in the text used for the simulations shown in Figure 9.

"Time constants for inactivation of the simulated currents. The time constants were obtained by fitting the decay of the simulated currents shown in Figure 9 to a double-exponential function as determined in Table 1.

' Ratio of the steady-state current $\left(I_{\mathrm{ss}}\right)$ over peak current $\left(I_{\text {peak }}\right)$ at $+40 \mathrm{mV}$ for the simulated currents shown in Figure 9. 
case of the slowly inactivating 37-37 current, macroscopic inactivation reflects primarily the entrance of these channels into the second inactivatcd statc $\left(I_{2}\right)$. Because of the presence of the type 37 amino domain, these channels can remain inactivated only by entering this second inactivated state $\left(I_{2}\right)$. The large value of the rate constant for the reverse reaction (from $I_{1}$ to $\mathrm{O}$ ) for channels with type 37 amino domains is also the main feature responsible for the time course of the "nontransient" current (i.e., 37-4). Because of the presence of the type 4 carboxyl domain, 37-4 channels enter the second inactivated state $\left(I_{2}\right)$ extremely slowly and thus cycle between the first inactivated state and the open state. The small apparent differences in times to peak (Iverson et al., 1988; see also Fig. 3), particularly evident if one compares 4-4 and 37-37 currents, are also produced by the model without introducing any differences in the rates of the activation steps. This suggests that these differences result from inactivation onset cutting short further current rise.

Although the model is probably not unique, it can serve as a basis to define further the roles of the amino and carboxyl domains on inactivation kinetics. Additional single-channel analyses, particularly studies using channels containing type 37 carboxyl domains and distributions of closed states, should provide tests of the model. For example, one would predict that channels containing the same amino domain, but different carboxyl domains, should exhibit little differences in their mean open times and their initial bursting behavior. Furthermore, all channels containing type 37 carboxyl domains should show an eventual reduction in the number of bursts per unit time resulting from the entrance of these channels into the absorbing inactivated state $\left(\mathrm{I}_{2}\right)$.

\section{References}

Adams PR, Galvan M (1986) Voltage-dependent currents of vertebrate neurons and their role in membrane excitability. In: Basic mechanisms of the epilepsies (Delgado-Escueta A, Ward AA, Woodbury DM, Porter R, eds). pp 137-170. New York: Raven.

Aldrich RW, Stevens CF (1987) Voltage-dependent gating of single sodium channels from mammalian neuroblastoma cells. J Neurosci $7: 418-431$.

Aldrich RW, Corey DP, Stevens CF (1983) A reinterpretation of mammalian sodium channel gating based on single-channel recording. Nature 306:436-441.

Armstrong CM, Bezanilla F (1977) Inactivation of the sodium channel. II. Gating current experiments. J Gen Physiol 70:567-590.

Baumann A, Grupe A, Ackermann A, Pongs O (1988) Structure of the voltage-dependent potassium channel is highly conserved from Drosophila to vertebrate central nervous systems. EMBO J 7:24572463.

Butler A, Wei A, Baker K, Salkoff L (1989) A family of putative potassium channel genes in Drosophila. Science 243:943-947.

Byerly L, Leung H-T (1988) Ionic currents of Drosophila neurons in embryonic cultures. J Neurosci 8:4379-4393.

Catterall WA (1986) Voltage-dependent gating of sodium channels: correlating structure and function. Trends Neurosci 9:7-10.

Dumont JN (1972) Oogenesis in Xenopus laevis (Daudin). I. Stages of oocyte development in laboratory maintained animals. J Morphol 136:153-180.

Elkins T, Ganelzky B, Wu C-F (1986) A Drosophila mutation that eliminates a calcium-dependent potassium current. Proc Natl Acad Sci USA 83:8415-8419.

Guy HK, Seetharamulu P (1986) Molecular model of the action potential sodium channel. Proc Natl Acad Sci USA 83:508-512.

Hamill OP, Marty A, Neher E, Sakmann B, Sigworth FJ (1981) Improved patch-clamp techniques for high resolution current recording from cells and cell-free membrane patches. Pfluegers Arch 391:85100 .

Haugland FN (1987) A voltage clamp analysis of membrane potassium currents in larval muscle fibers of Shaker mutants of Drosophila. Ph.D. thesis, University of Iowa, Iowa City, IA.
Haugland FN, Wu C-F (1986) Gene-dosage effects on a K current in Drosophila. Biophys J 49:168a.

Haugland FN, Wu C-F (1990) A voltage-clamp analysis of gene-dosage effects of the Shaker locus on larval muscle potassium currents in Drosophila. J Neurosci 10:1357-1371.

Hille B (1984) Ionic channels of excitable membranes. Sunderlan, MA: Sinauer.

Hoshi T, Aldrich RW (1988) Gating kinetics of four classes of voltagedependent $\mathrm{K}^{+}$channels in pheochromocytoma cells. J Gen Physiol 91:107-131.

Hoshi T, Zagotta WN, Aldrich RW (1989) Mutations in the amino terminal variable domain alter inactivation of Shaker B potassium channels in Xenopus oocytes. Soc Neurosci Abstr 15:338.

Iverson LE, Tanouye MA, Lester HA, Davidson N, Rudy B (1988) Expression of A-type $\mathbf{K}$ channels from Shaker cDNAs. Proc Natl Acad Sci USA 85:5723-5727.

Kamb A, Iverson LE, Tanouye MA (1987) Molecular characterization of Shaker, a Drosophila gene that encodes a potassium channel. Cell 50:405-413.

Kamb A, Tseng-Crank J, Tanouye MA (1988) Multiple products of the Drosophila Shaker gene may contribute to potassium channel diversity. Neuron 1:421-430.

Klein M, Camardo J, Kandel ER (1982) Serotonin modulates a specific potassium current in the sensory neurons that show presynaptic facilitation in Aplysia. Proc Natl Acad Sci USA 79:5713-5717.

Llinás R (1984) Comparative electrobiology of mammalian central neurons. In: Brain slices (Dingledine R, ed), pp 7-24. New York: Plenum.

MacKinnon R, Miller C (1989) Mutant potassium channels with altered binding of charybdotoxin, a pore-blocking peptide inhibitor. Science 245:1382-1385.

MacKinnon R, Reinhart PH, White MM (1988) Charybdotoxin block of Shaker $\mathrm{K}^{+}$channel suggests that different types of $\mathrm{K}^{+}$channels share common structural features. Neuron 1:997-1001.

Mathew MK, Ramaswami M, Gautam M, Kamb A, Rudy B, Tanouye MA (1989) Cloning and characterization of human $\mathrm{K}^{+}$channel genes. Soc Neurosci Abst 15:540.

McCormack K, Ramaswami M, Mathew MK, Tanouye MA, Iverson L, McCormack T, Rudy B (1989) Shaker potassium channels: a leucine zipper motif may indicate a site for subunit interaction and gating. Soc Neurosci Abstr 15:337.

McCormack K, Rudy B, Ramaswami M, Mathew MK, Iverson LE, McCormack TJ, Tanouye M (1990a) Mutagenesis of Shaker potassium channels: what's behind the zipper? Biophys J 57:210a.

McCormack K, Lin J-W, Ramaswami M, Tanouye MA, Iverson L, Rudy B (1990b) Heteromultimer formation can produce a large number of distinct potassium channels. 34th Ann Biophys Soc Abstr (in press).

Noda M, Shimizu S, Tanabe T, Takai T, Kayano T, Ikeda T, Takahashi H, Nakayama H, Kanaoka Y, Minamino N, Kangawa K, Matsuo H, Raftery MA, Hirose T, Inayama S, Hayashida $H$, Miyata $T$, Numa S (1984) Primary structure of Electrophorus electricus sodium channel deduced from cDNA sequence. Nature 312:121-127.

Noda M, Ikeda T, Kayano T, Suzuki H, Takashima H, Kurasaki M, Takahashi H, Numa S (1986) Existence of distinct sodium channel messenger RNAs in rat brain. Nature 320:188-192.

Pongs O, Kecskemethy N, Muller K, Krah-Jentgens I, Baumann A, Kiltz HH, Canal I, Llamazares S, Ferrus A (1988) Shaker encodes a family of putative potassium channel proteins in the nervous system of Drosophila. EMBO J 7:1087-1096.

Rudy B (1976) A kinetic model for slow inactivation in nerves. Biophys J 17:45a.

Rudy B (1978) Slow inactivation of the sodium conductance in squid giant axons. Pronase resistance. J Physiol (Lond) 283:1-21.

Rudy B (1981) Inactivation in Myxicola giant axons responsible for slow and accumulative adaptation phenomena. J Physiol (Lond) 312: 531-549.

Rudy B (1988) Diversity and ubiquity of K channels. Neuroscience 25:729-750.

Salkoff LB, Wyman RJ (1983) Ion currents in Drosophila flight muscles. J Physiol (Lond) 337:687-709.

Schwarz TL, Tempel BL, Papazian DM, Jan YN, Jan LY (1988) Multiple potassium-channel components are produced by alternative splicing at the Shaker locus in Drosophila. Nature 331:137-142.

Solc CK, Aldrich RW (1988) Voltage-gated potassium channels in larval CNS neurons of Drosophila. J Neurosci 8:2556-2570. 
Solc CK, Zagotta WN, Aldrich RW (1987) Single-channel and genetic analyses reveal two distinct A-type potassium channels in Drosophila. Science 236:1094-1098.

Tempel BL, Jan YN, Jan LY (1988) Cloning of a probable potassium channel gene from mouse brain. Nature 332:837-839.

Timpe LC, Schwarz TL. Tempel BL, Papazian DM, Jan YN, Jan LY (1988a) Expression of functional potassium channels from Shaker cDNA in Xenopus oocytes. Nature 331:143-145.

Timpe LC, Jan YN, Jan LY (1988b) Four cDNA clones from the Shaker locus of Drosophila induce kinetically distinct A-type potassium currents in Xenopus oocytes. Neuron 1:659-667.

Wu C-F, Haugland FN (1985) Voltage-clamp analysis of membranc currents in larval muscle fibers of Drosophila: alteration of potassium currents in Shaker mutants. J Neurosci 5:2626-2640.
Zagotta WN, Aldrich RW (1990) Voltage-dependent gating of Shaker A-type potassium channels in Drosophila muscle. J Gen Physiol 95: $29-60$.

Zagotta WN, Brainard MS, Aldrich RW (1988) Single-channel analysis of four distinct classes of potassium channels in Drosophila muscle. J Neurosci 8:4765-4779.

Zagotta WN, Germeraad S, Garber SS, Hoshi T, Aldrich RW (1989a) Properties of $S h$ B A-type potassium channels expressed in Shaker mutant Drosophila by germline transformation. Neuron 3:773-782.

Zagotta WN, Hoshi T, Aldrich RW (1989b) Gating of single Shaker potassium channels in Drosophila muscle and in Xenopus oocytes injected with Shaker mRNA. Proc Natl Acad Sci USA 86:7243-7247. 